\title{
Salix spp. as a biomass crop: Investigating their potential on marginal lands and the use of biochar as a soil amendment
}

\author{
Heather A. Nobert
}

Follow this and additional works at: https://researchrepository.wvu.edu/etd

\section{Recommended Citation}

Nobert, Heather A., "Salix spp. as a biomass crop: Investigating their potential on marginal lands and the use of biochar as a soil amendment" (2015). Graduate Theses, Dissertations, and Problem Reports. 6325. https://researchrepository.wvu.edu/etd/6325

This Thesis is protected by copyright and/or related rights. It has been brought to you by the The Research Repository @ WVU with permission from the rights-holder(s). You are free to use this Thesis in any way that is permitted by the copyright and related rights legislation that applies to your use. For other uses you must obtain permission from the rights-holder(s) directly, unless additional rights are indicated by a Creative Commons license in the record and/ or on the work itself. This Thesis has been accepted for inclusion in WVU Graduate Theses, Dissertations, and Problem Reports collection by an authorized administrator of The Research Repository @ WVU. For more information, please contact researchrepository@mail.wvu.edu. 


\title{
Salix spp. as a biomass crop:
}

\section{Investigating their potential on marginal lands and the use of biochar as a soil amendment}

\author{
Heather A. Nobert
}

Thesis submitted to the Davis College of Agriculture, Natural Resources, and Design at West Virginia University

in partial fulfillment of the requirements for the degree of

Master of Science in Forestry

\author{
Dave McGill, Ph.D., Chair \\ Shawn Grushecky, Ph.D. \\ Jeffery Skousen, Ph.D. \\ Jamie Schuler, Ph.D. \\ Morgantown, WV \\ 2015
}

Keywords: Salix, willow, biochar, marginal land, surface mine 


\begin{abstract}
Salix spp. as a biomass crop: Investigating its potential on marginal lands and the use of biochar as a soil amendment.
\end{abstract}

Heather A. Nobert

Energy consumption has drastically increased over the past 150 years and the pressure put on the environment to provide these resources has increased as a consequence. At least 2.5 million hectares of land in the United States has been disturbed as a result of surface mining for coal. Biomass crops have been explored as an alternative energy source. In West Virginia little land is available for those crops; however as a result of coal extraction, at least 50,000 acres of previously strip or surface mined area has been deemed suitable for reclamation with biomass crops. Due to the challenges associated with the reclamation of mine sites, biochar was investigated for its potential as a soil amendment. Field trials of shrub willow (Salix spp.) were established at four sites in West Virginia to assess their potential production in these highly disturbed sites. To characterize their potential as a feedstock for fuels, thermogravimetric analysis, analysis of elemental concentrations, and heating value were measured. Wood properties for 1 year old material were generally within the specifications for woody biomass. Ash content was slightly higher $(2.7 \%$ vs. $1 \%)$ as was nitrogen ( $0.98 \%$ vs. $0.35 \%)$. Volatile matter was lower than general a guideline $(79.8 \%$ vs. $82 \%)$ which is beneficial for heating values and greenhouse gas emissions. It was also observed that biochar was an effective soil amendment. Test plots that received applications of biochar had higher growth, yield, and survivorship than reference plots at the end of the first year. 


\section{Acknowledgements}

First and foremost I would like to thank my advisors and committee members, Dr. Dave McGill, Dr. Shawn Grushecky, Dr. Jeffery Skousen, and Dr. Jamie Schuler for their patience, encouragement, and feedback throughout this journey. Thanks to Dr. Ida Holaskova for her help with statistical modelling. I couldn't have done it without you.

Many thanks to the research and field assistants who helped to establish field trials and collect

data: Larry Osborn, Jeffery Slahor, Kandace Burton, John Files, Eric Hall, and Nick Wilkins. The success of this project would not have been possible without your help.

Finally, I would like to acknowledge my friends and family who have encouraged me and believed in me even when I didn't believe in myself. Thank you. 


\section{Table of Contents}

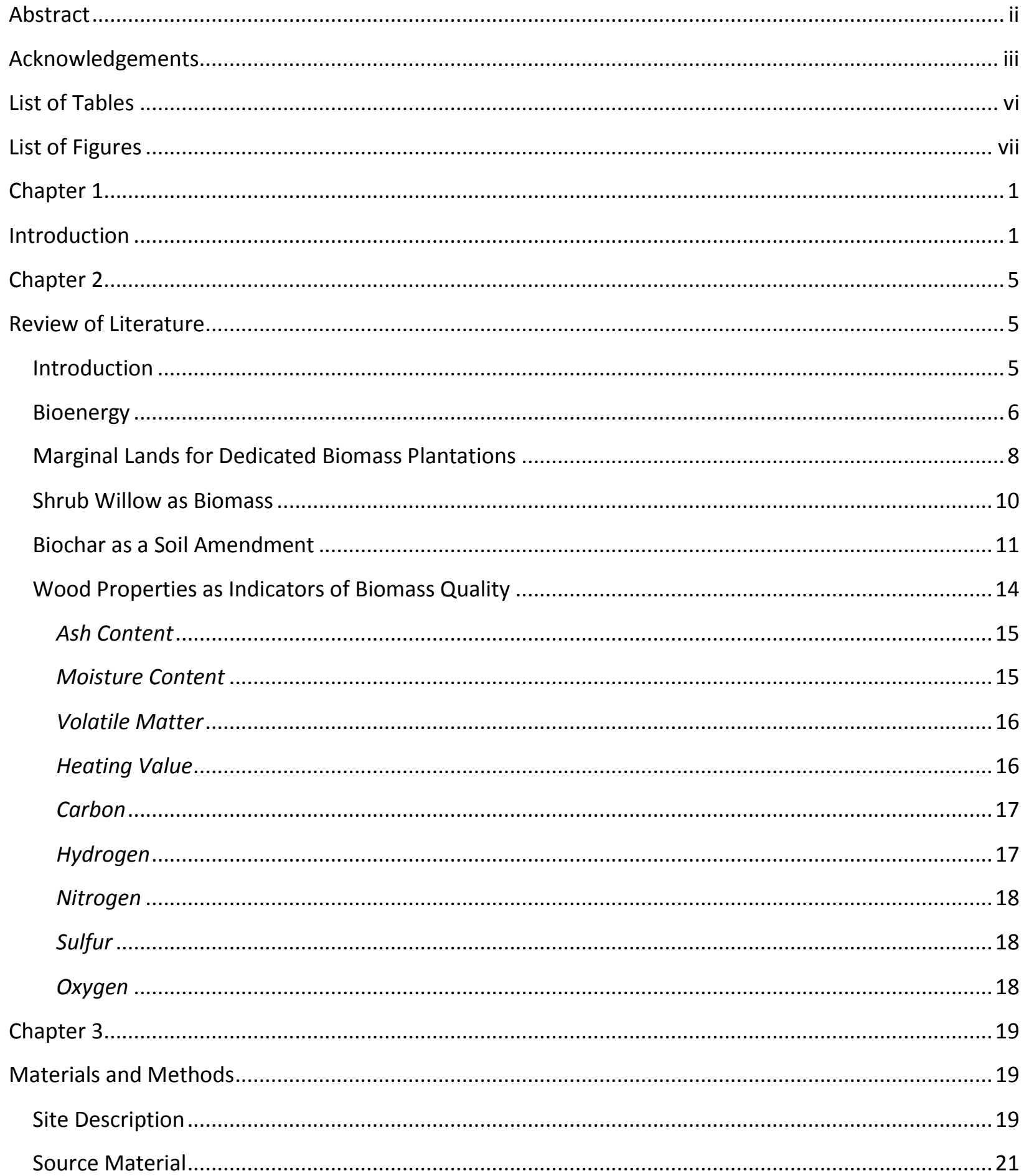




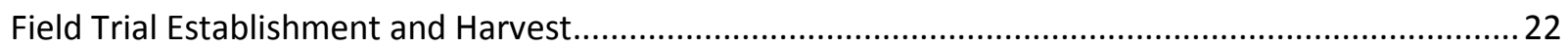

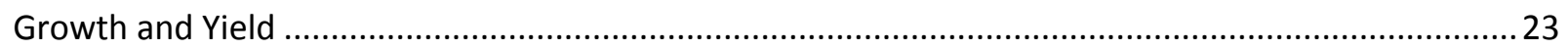

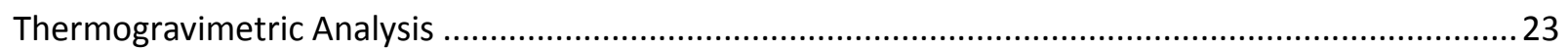

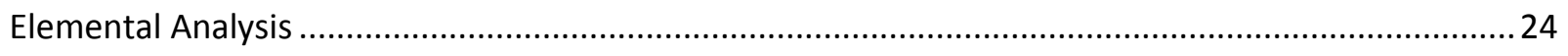

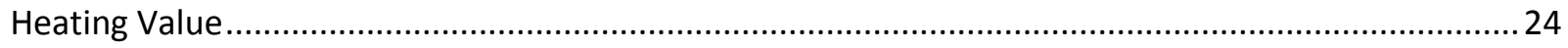

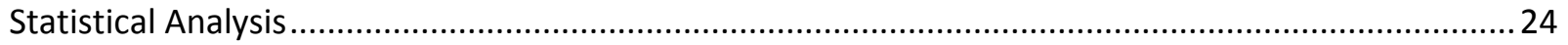

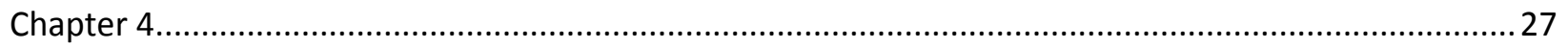

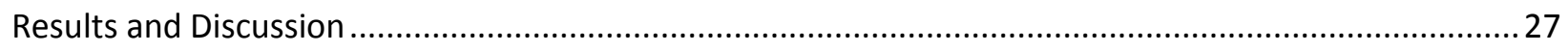

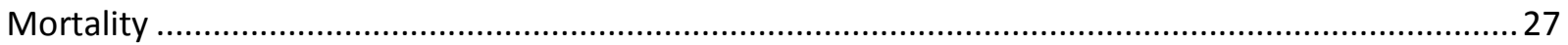

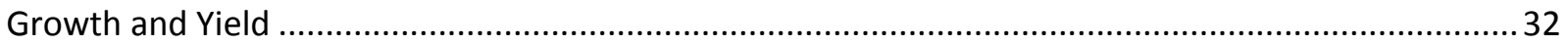

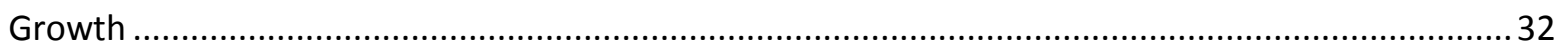

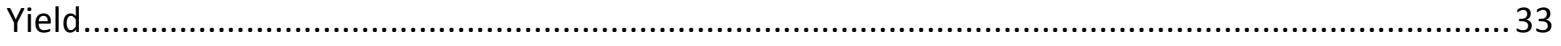

Thermogravimetric Analysis of Biomass Composition ..................................................................... 36

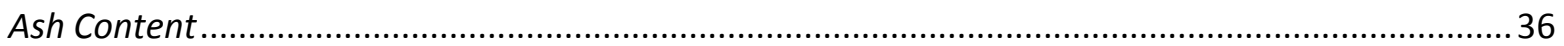

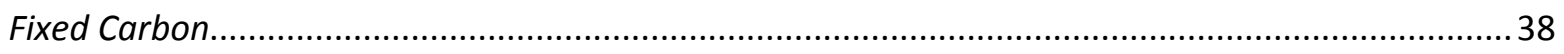

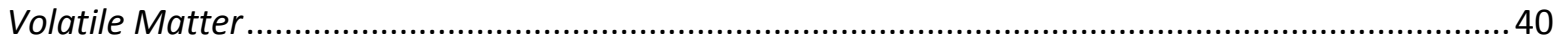

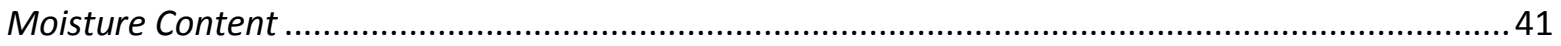

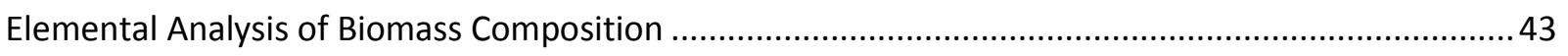

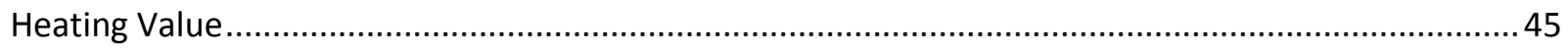

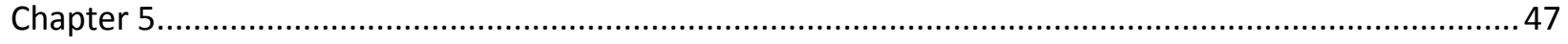

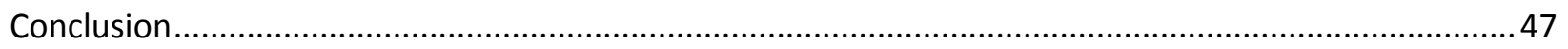

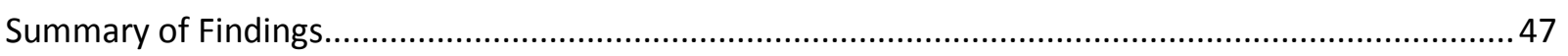

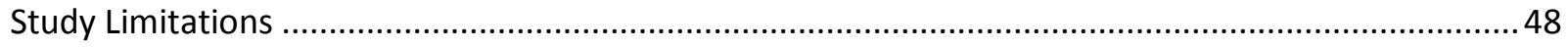

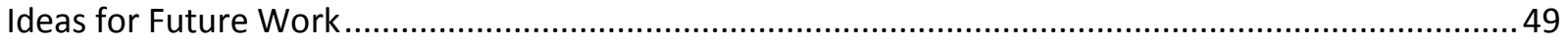

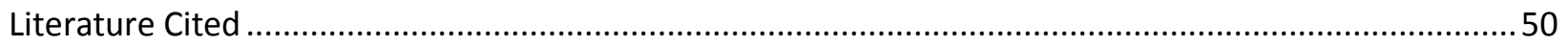




\section{List of Tables}

Table 1. Biomass yields from Salix biomass field trials................................................................... 12

Table 2. Literature review of wood properties measured through thermogravimetric analysis.............. 14

Table 3. Heating values of Salix wood as reported in the literature. .................................................. 16

Table 4. Elemental concentrations of Salix wood in percent weight as reported in the literature........... 17

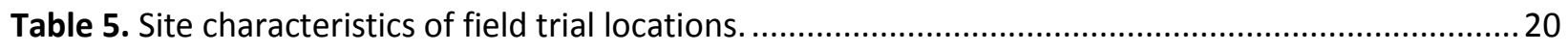

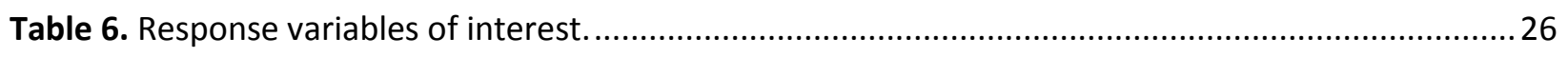

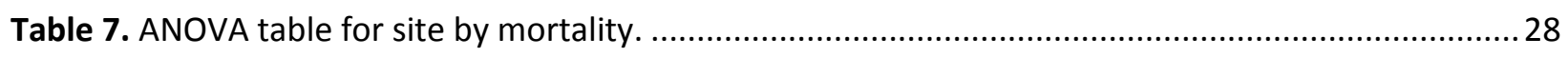

Table 8. Count of survivorship for each site, treatment, and cultivar............................................29-30

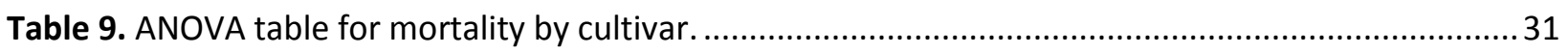

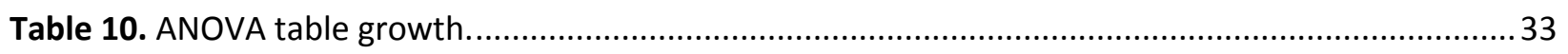

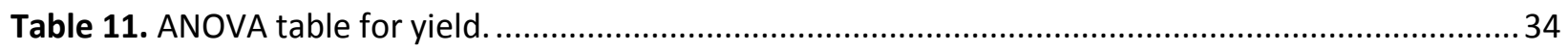

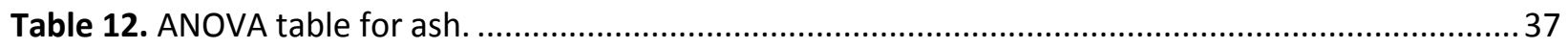

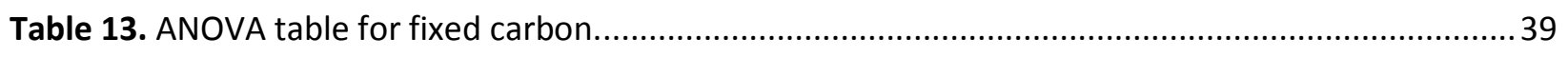

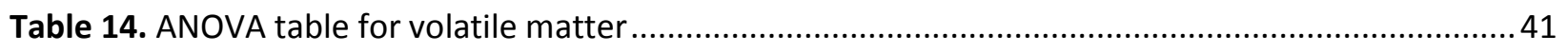

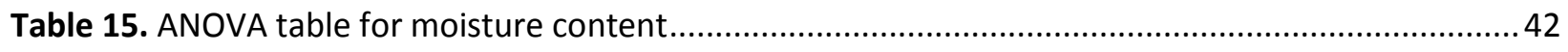

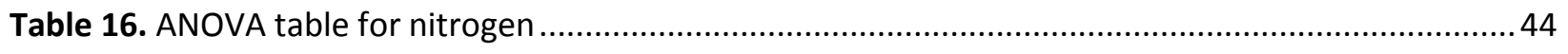

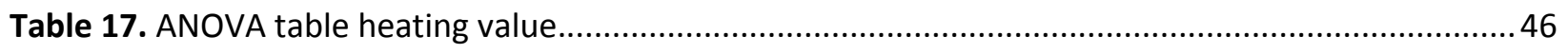




\section{List of Figures}

Figure 1. Site map of field trials in West Virginia, USA.................................................................. 19

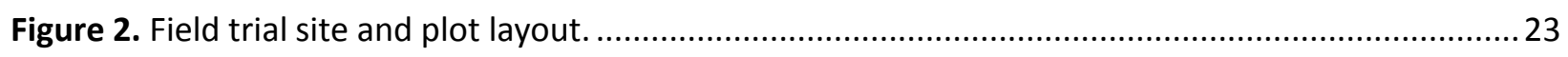

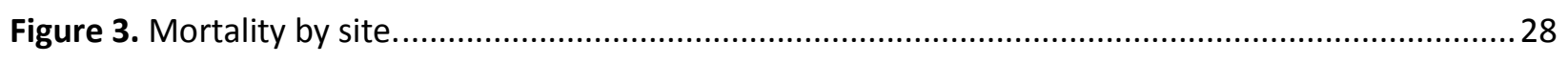

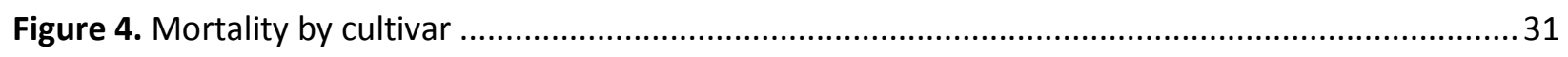

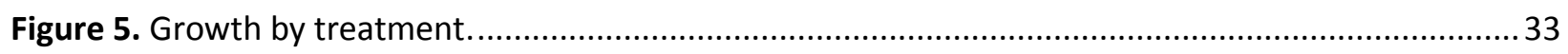

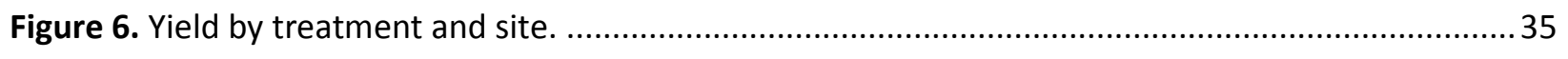

Figure 7. A significant site by treatment by variety effect for yield. ................................................ 35

Figure 8. Site by treatment by variety interaction for ash content ( $\%$ weight) ..................................... 38

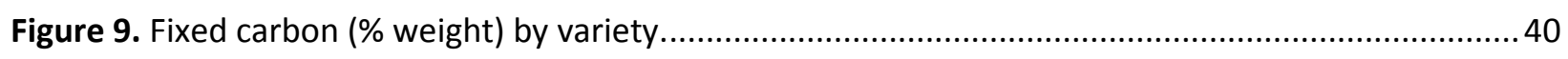

Figure 10. Volatile matter (\% weight) by site, treatment, and variety............................................. 41

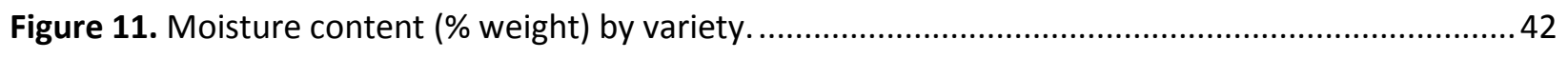

Figure 12. Nitrogen (\% weight) by site type and treatment........................................................... 44

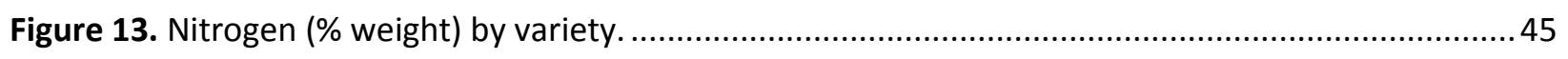

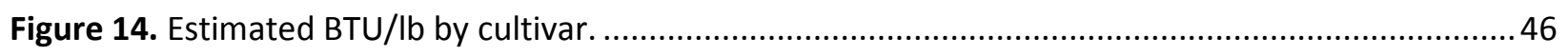




\section{Chapter 1}

\section{Introduction}

Surface mining for coal has disturbed approximately 2.5 million hectares in the United States (Emerson et al., 2008). In 1977 the Surface Mining Control and Reclamation Act (SMCRA) was passed. This federal legislation regulates surface mining and ensures proper reclamation of disturbed land. West Virginia however, has been regulating mine reclamation since 1939 when the West Virginia Department of Mines required bonds to be paid by mine operators to ensure reclamation was accomplished (Skousen, 2013). At least 200,000 acres of land in West Virginia have been strip/surface mined and at least 50,000 acres of that are suitable for reclamation with cultivation biomass crops (Grushecky et al., 2013). Biomass/bioenergy is derived from living or recently living biological material. Short rotation woody crops (SRWCS) are a type of biomass crop that have been identified as suitable for strip mine reclamation. Biomass, specifically SRWCS, grown on previously mined lands would help achieve the goals set forth by legislature regulating coal mining and reclamation with environmental and economic benefits.

Energy consumption has drastically increased in the past 150 years and consequently so has carbon dioxide emissions (Lemus and Lal, 2005). Two thirds of carbon dioxide emissions in the United States are the result of transportation emissions and fossil fuel power generation (Cook and Beyea, 2000). The government has recognized the need to increase energy efficiency, utilize alternative carbon neutral energy sources, and increase sequestration of carbon in a variety of ecosystems (i.e. agricultural, forest) (Cook and Beyea, 2000). The 
development of biomass crops can address these issues and has the potential to decrease the carbon footprint of the nation as a whole. Bioenergy is a greenhouse gas emission neutral alternative: the carbon dioxide captured in the photosynthetic process of plant growth is approximately equal to the carbon dioxide released in the combustion process to create biofuels (Borzecka-Walker et al., 2008). Additional motivation for development of bioenergy sources include air quality improvement, ecological and biodiversity preservation on agricultural and forested lands, increase in national security and decrease in foreign dependence for petroleum, and promotion of markets for waste and low quality wood (Cook and Beyea, 2000).

West Virginia has set a standard of $25 \%$ renewable energy from a variety of sources, including biomass, by 2025 (US Department of Energy, 2013). Shrub willow (Salix spp.) is a SRWC and a focus of the NEWBio (Northeast Woody/Warm-season Biomass) Consortium, of which West Virginia University is one among many education and industry partners. NEWBio aims to develop the biomass and bioenergy markets in the northeastern United States through a three part approach which investigates (1) human systems, (2) feedstock improvement, and (3) harvest, preprocessing, and logistics (NEWBio, 2012).

Shrub willows are tolerant of a variety of growing conditions and are naturally found across a broad geographical range (Volk et al., 2006). They are quickly and easily propagated from cuttings, have extensive and diffuse root systems, have a rapid juvenile growth rate, and are tolerant of high planting densities (Volk et al., 2006). Furthermore, they produce high yields within a few years of planting and re-sprout following harvest (a practice known as coppice) for 
at least 20 years (Volk et al., 2004). Little work has been done in West Virginia regarding the growth of SRWCs on abandoned mine lands and fallow agricultural fields.

Shrub willows have the potential to improve land quality and value. Shrub willow and SRWCs in general can improve soil characteristics such as structure, $\mathrm{pH}$, and nutrient cycling (Lemus and Lal, 2005). The rapid growth rate of willow is appealing because canopy cover is important in reducing soil temperature which in turn supports plant growth (Peek, 1970). The leaf litter that falls at the end of every growing season also returns carbon to the soil. The cumulative effects of these factors enhance the soil organic carbon sink capacity (Lemus and Lal, 2005; Volk et al., 2004). Furthermore, there are a variety of willow cultivars, thus a broad genetic base, which promotes resistance to disease and pests (Lemus and Lal, 2005; Volk et al., 2004). Additional benefits of willow plantations include wildlife use for forage and nesting habitat (Volk et al., 2004).

Fallow fields and abandoned mine lands, are often referred to as marginal lands. These lands usually have limitations that produce lower yields and/or poorer quality crops, making them economically marginal for food production. Limitations can be related to site and soil conditions such as slope, moisture, compaction, rockiness, $\mathrm{pH}$, nutrient deficiencies, salinity, etc. (Wicke, 2011). Growing bioenergy crops on marginal lands is desirable because the prime agricultural lands can and should be used for food crops rather than growing bioenergy crops. Additionally, there are economic benefits to landowners who choose to grow bioenergy crops on their marginal lands.

In order to improve fertility and soil conditions on marginal lands, the use of biochar has been investigated as a soil amendment. Biochar is a by-product of pyrolysis (the carbonization 
of biomass under high heat, low oxygen conditions). It is comparable to finely ground charcoal (International Biochar Initiative, 2014). Its capacity to enhance plant growth and sequester carbon in the soil as a long term sink has been demonstrated in several field studies (Kwapinski et al., 2010; Lehmann et al., 2006; Major et al., 2010) by retaining and releasing nutrients that enhance plant growth and yield, increasing soil quality by adding carbon which is resistant to microbial degradation, and increasing water holding capacity (Kwapinski et al., 2010). Biochar can particularly improve the quality and fertility of marginal soils by improving their potential for plant growth. Therefore, the use of biochar on marginal lands can improve yield of bioenergy crops grown on these lands.

Little work has been done to date on shrub willow as a bioenergy crop in West Virginia. Similarly, there is a lack of literature on impacts of biochar on bioenergy crops. Given the information gap on these topics, a project was designed and carried out to expand the knowledge base for biochar and shrub willow bioenergy development in the state. The project objectives were:

Objective I: Determine the yield differences between shrub willow cultivars on marginal lands through mortality, growth, and yield analysis.

Objective II: Determine the effects of biochar as a soil amendment to shrub willow growth, yield, and quality as a bioenergy crop. 


\section{Chapter 2}

\section{Review of Literature}

\section{Introduction}

Energy is closely linked to quality of life. As of 2008, fossil fuels provided $85 \%$ of energy

worldwide (Arvizu et al., 2011). The United States is the largest consumer of primary energy, consuming over 100 quadrillion BTU (one BTU is equal to the amount of energy required to raise the temperature of one pound of water by one degree Fahrenheit) annually (U.S. EIA, 2013). Approximately two thirds of the human produced carbon dioxide in the United States is a result of fossil fuel power generation and transportation (Cook and Beyea, 2000).

Internationally, it is recognized that greenhouse gas emissions are the driving factor of climate change, thus reduction of greenhouse gas emissions and limiting global temperature increase have been identified as primary objectives to mitigate climate change (Arvizu et al., 2011; Chum et al., 2011; Cook and Beyea, 2000). Renewable energy, any form of energy that is replenished by natural processes at a rate that is equal to or exceeds its rate of use, is an approach to climate change mitigation (Arvizu et al., 2011).

Energy produced from biomass accounts for $10.2 \%$ of global primary, yet only $1.3 \%$ of energy in the United States. These statistics however are increasing annually (Arvizu et al., 2011; U.S. EIA, 2014). Salix or shrub willow is a type of woody biomass used throughout the Northeast, Mid-Atlantic, and Midwest regions of the United States as a dedicated biomass feedstock. Some of the challenges to scale-up biomass systems include land availability, suitability of available land for growing biomass crops, and feedstock reliability. 
This is a review of the literature on Salix as a biomass feedstock and the use of biochar as a soil amendment to improve growth and yield in field trials. It includes a synthesis of parameters used to evaluate the effectiveness of willow as a biomass feedstock.

\section{Bioenergy}

Bioenergy is energy that is contained within living or recently living organisms. This definition explicitly excludes fossil fuels. Bioenergy is a fossil fuel alternative that addresses issues associated with both fossil fuel power generation and transportation emission. It is lower in carbon dioxide and other greenhouse gas emissions than fossil fuels (Arvizu et al., 2011). The carbon dioxide released during harvest, transportation, production, and conversion of woody biomass is roughly equal to the amount of carbon dioxide taken up by the crop during growth resulting in a carbon neutral fuel alternative (Borzecka-Walker et al., 2008; Volk et al., 2006). Globally, bioenergy accounts for $10.2 \%$ of the $12.9 \%$ of renewable primary energy (Arvizu et al., 2011). While this appears to be a significant portion of renewable energy generated from biomass, it is important to note that only $38 \%$ is derived from modern biomass with the rest coming from traditional biomass used in cooking and heating, mainly in developing countries (Arvizu et al., 2011). Additional motivation for developing biomass as a renewable energy includes energy security, decreased air and water pollution, decreased wind and water erosion, ecological and biodiversity preservation, increased soil carbon sequestration, improved soil productivity, decreased detrimental health and environmental impacts, and promotion of local economies (Arvizu et al., 2011; Chum et al., 2011; Cook and Beyea, 2000).

In addition to carbon dioxide emissions, fossil fuels release high amounts of sulfate, nitrate, and mercury emissions that contribute to the overall greenhouse gas profile and have 
negative impacts on environmental and human health (Abrahamson et al., 1998; Heller et al., 2004). These emissions can also be reduced by transitioning from fossil fuels to biomass. Cofiring of biomass with coal generally occurs at a 10\% co-firing rate (Baxter and Koppejan, 2005; Heller et al., 2004) but have been tested at rates of 5\% and 15\% (Mann and Spath, 2001). Biomass has low sulfur content and can thus significantly reduce sulfate emissions relative to the sulfur content in the fuel (Baxter and Koppejan, 2005; Heller et al., 2004). For every percent of fossil fuel replaced with wood biomass in a co-fired coal facility, sulfate emissions are reduced by $1 \%$ and nitrate emissions are reduced by $0.5-1.5 \%$ (Abrahamson et al., 1998). Furthermore, mercury emissions were reduced $8.4 \%$ in a co-firing setting (Heller et al., 2004). Additional benefits of co-firing biomass with coal at a $10 \%$ co-firing rate include an increase in the net energy ratio of $8.9 \%$ (electricity delivered/total fossil fuels consumed) and a potential decrease in net global warming of 7-10\%. Biomass, including Salix, should therefore be considered a valuable part of the puzzle in discussions of renewable energy and greenhouse gas emission mitigation.

There is growing concern about the carbon footprint of biomass (Manomot Center for Conservation Sciences, 2010). Biomass emits more greenhouse gasses per unit of energy than fossil fuels however over time the carbon captured in the regrowth of biomass lowers the carbon debt created by utilizing biomass energy. At some future point the carbon debt is paid off and biomass combustion begins yielding carbon "dividends" resulting in greenhouse gas emissions that are lower than if fossil fuel combustion were to have continued. The magnitude of the carbon debt and the time frame required to being producing carbon dividends depends on the type of biomass used, combustion technology, and the fossil fuels it replaces. Given the 
long term nature of greenhouse gas emissions, projections for the benefits of biomass are often examined on the scale of tens of years, in which biomass clearly becomes beneficial over fossil fuels (Manomot Center for Conservation Sciences, 2010). Despite the benefits of biomass, it will not become widely accepted without regulatory or legislative incentive (Abrahamson et al., 1998; Cook and Beyea, 2000; Heller et al., 2004). At current pricing, the potential to produce energy from biomass chips is low (Manomot Center for Conservation Sciences, 2010).

Additional barriers to biomass acceptance and commercialization include production costs, land demands, and a general lack of knowledge and demonstrations of successful biomass systems (Abrahamson et al., 1998; Chum et al., 2011; Cook and Beyea, 2000).

\section{Marginal Lands for Dedicated Biomass Plantations}

In order for biomass systems to be widely implemented, biomass plantations are needed to meet growing demand. Currently marginal lands are being explored as potential sites for biomass plantations and have been identified as the next best alternative for biomass production, following dedicated surplus agricultural land (Chum et al., 2011). The term marginal land has many definitions. It can be considered land that is degraded; where production capacity has declined temporarily or permanently; barren; rough; inaccessible; fallow; have by undesirable characteristics; and/or yields little profit (Chum et al., 2011; Peterson and Galbraith, 1932; Tang et al., 2010; Wicke, 2011). Due to its variable nature, it is important to define marginal land in context (Peterson and Galbraith, 1932).

Marginal lands vary in severity and reason for marginality. Consequently, issues associated with productivity vary by site. Some causes of marginality include salinity, overgrazing, metal contamination, and deforestation or forest degradation as a result of 
logging. (Wicke, 2011). Under proper management, the negative impacts of these problems can be moderated. Management at any given location depends on crop type, soil conditions, climate, and social and economic objectives (Campbell et al., 2008).

Marginal land for biomass crop production is of interest because it addresses issues associated with food security as well as deforestation. It is a unique solution to avoid deforestation associated with land use change for the cultivation of bioenergy crops, simultaneously avoiding converting prime agricultural land to bioenergy crop land (Campbell et al., 2008; Chum et al., 2011; Debolt et al., 2009, Tang et al., 2010). It is essential to promote bioenergy markets that do not interfere with food production since food-fuel competition decreases food security and increases food prices worldwide (Campbell et al., 2008). When forests are cleared for biomass crop production, large amounts of carbon are released into the atmosphere, accelerating climate change (Debolt et al., 2009).

The United States has been identified as the country with the highest potential for biomass crop production on marginal lands, followed by Brazil and Australia (Campbell et al., 2008). Worldwide, it is estimated that between 1.6 and 2.1 billion tons of above ground biomass could be produced annually on marginal lands. This would account for $7-8 \%$ of global primary energy (Campbell et al., 2008). In the United States, abandoned agricultural fields as well as mine lands have been identified as land types suitable for biomass (Debolt et al., 2009) and address climate change issues associated with land use change (Wicke, 2011). Benefits of using marginal lands for bioenergy crops also include increased biodiversity when monoculture is avoided; reduced erosion; increases in soil carbon and soil productivity; and improved rural economies (Chum et al.,2011; Debolt et al., 2009; Tang et al., 2010; Wicke, 2011). 


\section{Shrub Willow as Biomass}

Shrub willow is a short rotation woody crop (SRWC) of interest as a biomass feedstock.

Shrub willow grows across a wide geographic range, in part due to its adaptability to varied site conditions (Volk et al., 2006). Optimal growth conditions for willow are soil pH between 5.5 and 6.5 (Ledin, 1996; Tahvanainen and Rytkonen, 1999); 500 mm ( 20 in.) of rainfall annually (Borzecka-Walker et al., 2008); and slopes less than 8\% (Abrahamason et al., 1998). Shrub willows are tolerant of high planting densities and provide high biomass yields on a relatively small land base, when compared to traditional forestry (Volk et al., 2006). Plantations are temporary carbon sinks during plant growth. They sequester between 0.22 and 0.39 tons of carbon per hectare per year (Borzecka-Walker et al., 2008) resulting in a lower carbon footprint than fossil fuel extraction (Cook and Beyea, 2000). Shrub willows have many other characteristics that make them an ideal biomass crop. They are quickly and easily propagated from cuttings and have a rapid juvenile growth rate which is important during the establishment phase (Volk et al., 2006). Additionally, an extensive root system enables them to persist over several harvests, upwards of 20 years (Abrahamson et al., 1998; Volk et al., 2006). Furthermore, shrub willows have significant genetic diversity with the potential for rapid genetic improvement leading to more tolerant species and/or improved growth and yield (Volk et al., 2006).

The first commercial scale harvest of willow biomass in North America began in 2001/2002 (Volk et al., 2006). Willow has been shown to produce a high yield within a few years of establishment and resprout after multiple harvests (a practice known as coppice) for at least 20 years (Abrahamson et al., 1998; Borzecka-Walker et al., 2008; Cook and Beyea, 2000; Dimitriou and Aronsson; Labrecque and Teodorescu 2003, 2005; Tahvaninen and Rytkonen, 
1999; Vande Walle et al., 2007; Volk et al., 2004; Volk et al., 2006). Biomass production of coppice willow is highly variable. Average yields are between 11.8 and 16.9 tons hectare ${ }^{-1}$ year $^{-}$ ${ }^{1}$. Studies from temperate climates produce results as low as 2.42 tons dry matter ha ${ }^{-1} \mathrm{yr}^{-1}$ and as high as 31.86 tons dry matter ha-1 $\mathrm{yr}^{-1}$ (Table 1$)$.

In addition to dedicated biomass plantations, willows can also provide secondary environmental functions. Willows are commonly used as riparian buffers which can improve water quality and reduce erosion (Abrahamson et al., 1998; Volk et al., 2006). They can also serve as living snow fences and hyper-accumulators (Volk et al., 2006). Studies have shown that shrub willows are capable of taking up heavy metals and organic compounds from the soil, especially cadmium (Volk et al., 2006), making them especially attractive for degraded or polluted landscapes.

\section{Biochar as a Soil Amendment}

Biochars are solid, charred, materials obtained by carbonizing biomass. Biochars are produced through a process known as pyrolysis which occurs at very high temperatures, between $300^{\circ}$ and $1000^{\circ} \mathrm{C}$, with limited oxygen (Kahru et al., 2011; Lehmann et al., 2006). Biochars are characterized by their stability (Draper and Tomlinson, 2012; Kwapinski et al., 2010), low porosity, low surface area (Lima et al., 2009), capacity to increase nutrient retention (Jones et al., 2012; Kwapinski et al., 2010; Major et al., 2010), decrease soil acidity (Jones et al., 2012; Major et al., 2010), and increase microbial activity (Jones et al., 2012; Rooney et al., 2009). Biochar is of interest not only because it has the potential to improve soil properties, but because it sequesters carbon in the soil (Jeffery et al., 2011; Kwapinksi et al., 2010). 
Furthermore, it has been proposed as a way to improve the quality of degraded lands (Fellet et al., 2011).

Table 1. Biomass yields from Salix biomass field trials in the United States and Europe, as reported in the literature

\begin{tabular}{|c|c|c|c|}
\hline Yield (tons/hectare/year) & Location & Site Conditions & Citation \\
\hline $12.36-19.77$ & New York, USA & moderately productive soil & Abrahamson et al., 1998 \\
\hline 11.1-13.7 & Poland & & Borzecka-Walker et al., 2008 \\
\hline $2.68-5.35$ & Sweden & & Dimitriou and Aronsson (2013) \\
\hline 14.62-15.42 & Quebec, Canada & sandy soil & Labrecque and Teodorescu, 2003 \\
\hline 28.54-31.86 & Quebec, Canada & clayey soil & Labrecque and Teodorescu, 2003 \\
\hline $6.21-16.90$ & Quebec, Canada & & Labrecque and Teodorescu, 2005 \\
\hline $2.42-6.18$ & Michigan, USA & & Miller and Bender, 2008 \\
\hline $16.03-26.35$ & southern Finland & best 3 sites of study & Tahvanainen and Rytkonen, 1999 \\
\hline 3.4 (actual)- & Flanders, & & \\
\hline 3.5(potential) & Belgium & & Vande Walle et al., 2007 \\
\hline
\end{tabular}

While there are numerous reports of biochar positively affecting plant growth and yield (Jeffery et al., 2011; Jones et al., 2012; Lehmann et al., 2006; Major et al., 2010; Solaiman et al., 2012), literature remains sparse with little consensus on best practices for application and effects on plant productivity. Application rates of less than 1 ton ha-1 to over 100 ton ha ${ }^{-1}$ have been reported (Fellet, et al., 2011; Jeffery et al., 2011; Jones et al., 2012; Major et al., 2010; Solaiman et al., 2012) and yield increases have been reported from less than $10 \%$ increase to over $200 \%$ increase (Major et al., 2010). In a quantitative review of current literature by Jeffery et al. (2011), no significant differences were observed between application rates of 10, 25, 50, 
and 100 ton $\mathrm{ha}^{-1}$, however all applications of biochar were statistically significant $(p>0.05)$ compared to the control. Solaiman et al. (2012) found that applications of 100 ton ha-1 generally had detrimental impacts on plant growth and yield. This was likely due to high concentrations of nutrients and elevated $\mathrm{pH}$. Applications less than 100 ton ha ${ }^{-1}$ had either no impact or increased growth and yield in his work. Jeffery et al. (2012) also noted that the overall increase in crop productivity was $10 \%$ regardless of treatment, soil type, or crop.

Effects of biochar application on growth and yield vary temporally (Jones et al., 2012; Major et al., 2010) and literature that reports yields beyond the first year of growth is limited. In work by Major et al. (2010), effects of biochar on maize yields did not result in significant differences in crop yield in year one. Significant differences in yield were reported in years 2-4 and increasing rates of biochar application $(0,8$, and 20 ton ha-1) produced increasing yields. Jones et al. (2012) investigated biochar applications of 0,25 , and 50 ton ha-1 on maize and hay grass (a common forage crop) productivity. Maize growth and yield was not affected by the applications of biochar however the grass responded to the applications in year three.

Biochar has positive effects on soil properties on both productive and degraded lands. Biochar has also demonstrated the capacity to immobilize metals and toxins in degraded soils (Draper and Tomlinson, 2012; Fellet et al., 2011). When applied to an agricultural soil, biochar decreased the uptake of aluminum by soybeans and maize (Major et al., 2010). Additionally, Lima et al. (2009) demonstrated that biochars, especially when produced from poultry litter, have the capacity to adsorb metal ions such as copper $\left(\mathrm{Cu}^{2+}\right)$ at a rate of $0.60-0.70 \mathrm{mmoles} / \mathrm{g}$ char, cadmium $\left(\mathrm{Cd}^{2+}\right)$ at 0.40-0.45 mmoles/g char, nickel $\left(\mathrm{Ni}^{2+}\right)$ at $0.25 \mathrm{mmoles} / \mathrm{g}$ char, and zinc 
$\left(\mathrm{Zn}^{2+}\right)$ at 0.40-0.70 mmoles/g char. These rates are significantly higher than those of fiber-based counterparts such as char produced from wood, coal, or coconut shell (Lima et al., 2009).

The effects of biochar on crop productivity and soil quality can be summarized as neutral to positive with no observable detrimental effects. It has the potential to greatly improve the physical properties of soils and is thus a valid option for soil remediation in many circumstances. Applications of biochar should be identified on a case by case basis.

\section{Wood Properties as Indicators of Biomass Quality}

Biomass has a wide array of physical properties (Ryu et al., 2006) and it is important to understand the composition of biomass feedstocks because composition plays a significant role in conversion efficiency (Serapiglia, et al., 2013). In general, biomass has higher oxygen and moisture content, lower ash and sulfur content, and a lower heating value than coal (Demirbas, 2004).

Table 2. Literature review of wood properties measured through thermogravimetric analysis. These wood properties are used to describe biomass quality as a fuel source. Citations are in brackets: [1] General guidelines for woody biomass by Demirbas, 2004; [2] Ryu, et al., 2003; [3] Ledin, 1996; [4] Tharakan, et al., 2003; [5] Serapiglia, et al., 2013; [6] Serapiglia, et al., 2013 (2); [7] Lebrecque, et al., 1997; [8] Prins et al., 2006; [9] Lange and Pellegrini, 2014.

\begin{tabular}{|c|c|c|c|c|c|c|c|c|c|c|}
\hline & & [1] & {$[2]$} & [3] & [4] & [5] & [6] & [7] & [8] & [9] \\
\hline Ash & & 1 & 1 & $1.0-1.2$ & $1.3-2.7$ & $0.5-4$ & $<3$ & $1.8-2.3$ & 1.6 & 1.71 \\
\hline Moisture & $\%$ & 50 & 7 & $46.2-50.3$ & 53 & & & & 8.6 & 50 \\
\hline $\begin{array}{l}\text { Volatile } \\
\text { Matter }\end{array}$ & weight & 82 & 78.1 & & & & & & 81.4 & 82.22 \\
\hline Fixed Carbon & & 17 & 13.7 & & & & & & & 16.07 \\
\hline
\end{tabular}

Salix spp. exhibits plasticity in that their physical characteristics are subject to variability based on environmental conditions, thus it can be said a genotype by environment interaction is observed in woody biomass feedstocks (Serapiglia et al., 2013). It is important to select cultivars appropriate for location based on their composition, growth, and yield (Serapiglia et 
al., 2013). Variation in wood properties may be due to variations in nutrient availability in soil, moisture stress, and/or fertilization rates (Serapiglia et al., 2013; Tharakan et al., 2003).

\section{Ash Content}

Low ash content is desirable and is an indicator of good quality wood for fuel (Tharakan, et al., 2003; Serapiglia, et al., 2013). Ash content is of interest because ash has the potential to create problems in combustion systems when concentrations are high (Ciolkosz, 2010). Woody material generally has lower ash than other sources (Ryu et al., 2006). A general guideline for woody biomass indicates that ash content is approximately $1 \%$ by weight (Table 2 ) (McKendry, 2002), compared to coal which is approximately $7 \%$ by weight (Demirbas, 2004). Ash content differed significantly between genotype and location in a New York study and variability was relatively high - around 57\% (Serapiglia et al., 2013). No correlation was observed between ash content and yield for either site (Serapiglia et al. 2013). The difference in ash content between sites is hypothesized to be related to nutrient availability in the soil (Serapiglia, et al., 2013). It is also interesting to note that ash content of willow is relatively low compared to other biofuels such as switchgrass (Tharakan et al., 2003).

\section{Moisture Content}

Low moisture content is a desirable characteristic for biomass feedstock (Labrecque et al., 1997; Tharakan, et al., 2003). Low moisture indicates that there is more heating value by mass and is more readily combustible (Ciolkosz, 2010). Fresh green matter is typically about $50 \%$ moisture (Table 2) (McKendry, 2002) in contrast to coal which typically has a moisture content of about 5\% (Demirbas, 2004). In a field trial in New York, Tharakan et al. (2003) report low variability in percent moisture and no significant differences between clones. 


\section{Volatile Matter}

Volatile matter or volatiles refers to the portion of solid fuel driven off as a gas when heated (McKendry, 2002). Volatile matter is an important factor to consider when designing a combustion system. Fuels with high volatile matter tend to vaporize before combusting ("flaming combustion") while fuels with low volatile matter tend to combust and burn as a "glowing char" which is more desirable (Ciolkosz, 2010). Guidelines indicate that approximately $82 \%$ volatile matter by weight can be expected for woody biomass (Table 2) (McKendry, 2002) compared to $2.5 \%$ by weight for coal (Demirbas, 2004).

\section{Heating Vallue}

High calorific value is a crucial characteristic for biomass feedstocks. The heating value or calorific content describes the total amount of energy available in the fuel and is generally a result of the chemical composition (Ciolkosz, 2010).

Table 3. Heating values (MJ/kg) of Salix wood as reported in the literature.

\begin{tabular}{lll} 
Heating Value & Location & Source \\
\hline $14-21 \mathrm{MJ} / \mathrm{kg}$ & General Guideline & McKendry, 2002 \\
$17.8 \mathrm{MJ} / \mathrm{kg}$ & United Kingdom & Ryu et al., 2006 \\
$19.7 \mathrm{MJ} / \mathrm{kg}$ & NE Europe & Ledin, 1996 \\
$19.21-19.59 \mathrm{MJ} / \mathrm{kg}$ & Quebec, Canada & Lebrecque et al., 1997 \\
$17.7-19.0 \mathrm{MJ} / \mathrm{kg}$ & New York, USA & Prins et al., 2006
\end{tabular}

General guidelines for woody biomass indicate that a heat value of $14-21 \mathrm{MJ} / \mathrm{kg}$ can be expected (Table 3) (Demirbas, 2004). Table 3 also presents heating values observed from 
several willow field trials. The typical heating value of coal is between 23 and $28 \mathrm{MJ} / \mathrm{kg}$

(Demirbas, 2004). In a field trial in Quebec, Canada, the calorific values of willow biomass did not differ significantly for either site or variety (Labrecque et al., 1997). Variations in heating value may vary between sites and cultivars as a result, natural variation among species, climate, and soil conditions (Ciolkosz, 2010).

\section{Carbon}

Carbon is the most important element in biomass fuels. It comes from atmospheric carbon dioxide sequestered by the plant during growth and converted to biomass. It directly impacts the heating value of the fuel. Carbon content of biomass is typically $42-54 \%$ by weight (Table 4) compared to coal which is from $65-85 \%$ by weight (Demirbas, 2004).

Table 4. Elemental concentrations of Salix wood in percent weight as reported in the literature. Citations are in brackets: [1] General guidelines from Demirbas, 2004; [2] Ledin, 1996; [3] Prins et al., 2006; [4] Ryu et al., 2006.

\begin{tabular}{lllll} 
Carbon & Hydrogen & Nitrogen & Sulfur & Oxygen \\
\hline $42-54[1]$ & $6-8[1]$ & $0.36[2]$ & $<0.5[1]$ & $35-45[1]$ \\
$48.4[2]$ & $6[2]$ & $0.34[3]$ & $0.03[2]$ & $45.2[2]$ \\
$47.2[3]$ & $6.1[3]$ & & $44.8[3]$ & $39.3[4]$ \\
$45.9[4]$ & $6.6[4]$ & & &
\end{tabular}

\section{Hydrogen}

Hydrogen is also a significant component of biomass. It is converted to $\mathrm{H}_{2} \mathrm{O}$ during the combustion process and contributes to the heating value. General guidelines indicate that hydrogen content of biomass is between 6 and $8 \%$ by weight (Table 4), in comparison with coal which is generally around $4 \%$ by weight (Demirbas, 2004). 


\section{Nitrogen}

Nitrogen is an essential nutrient for plant growth. Nitrogen is taken up during plant growth and concentrations will depend on soil conditions and fertilizer treatments. Nitrogen does not contribute to the heating value however nitrogen in fuels directly contributes to nitrate emissions and thus minimizing nitrogen in fuels is desirable (Demirbas, 2004). Nitrogen in coal is typically about $1.2 \%$ by weight (Table 4 ) (Demirbas, 2004).

\section{Sulfur}

Low sulfur content is an important fuel quality. Sulfur has little impact on the heating value of biomass however sulfur directly contributes to sulfate emissions. Woody biomass has lower sulfur content than coal, typically $<0.5 \%$ by weight (Table 4 ) compared to $0.5-7.5 \%$ by weight of coal (Demirbas, 2004).

\section{Oxygen}

Oxygen content is estimated by subtracting the values of $\mathrm{C}, \mathrm{H}, \mathrm{N}$, and $\mathrm{S}$ from 100 .

Oxygen content in biomass is typically $35-45 \%$ by weight (Table 4 ), compared to coal which is generally between 2 and $15 \%$ by weight (Demirbas, 2004). 


\section{Chapter 3}

\section{Materials and Methods}

Field trials were established in order to successfully test for production differences among willow varieties and biochar treatments. Assessment of willow varieties for quality as a bioenergy feedstock was completed upon conclusion of year one growth to meet objectives I and II.

\section{Site Description}

Trials were established in Morgantown, WV at the West Virginia University farm $\left(39^{\circ} 39^{\prime} 29.55^{\prime \prime} \mathrm{N}, 79^{\circ} 55^{\prime} 50.17^{\prime \prime} \mathrm{W}\right)$, in

Preston County at the Squires Creek No. 1 Mine $\left(39^{\circ} 28^{\prime} 41.03^{\prime \prime} \mathrm{N}, 79^{\circ} 46^{\prime} 59.81^{\prime \prime} \mathrm{W}\right)$, in Greenbrier County at the Buck Lilly Surface Mine $\left(38^{\circ} 1^{\prime} 7.31^{\prime \prime} \mathrm{N}, 80^{\circ} 35^{\prime} 23.05^{\prime \prime} \mathrm{W}\right)$, and in Mason County at the West Virginia Division of Forestry Clements State Tree Nursery

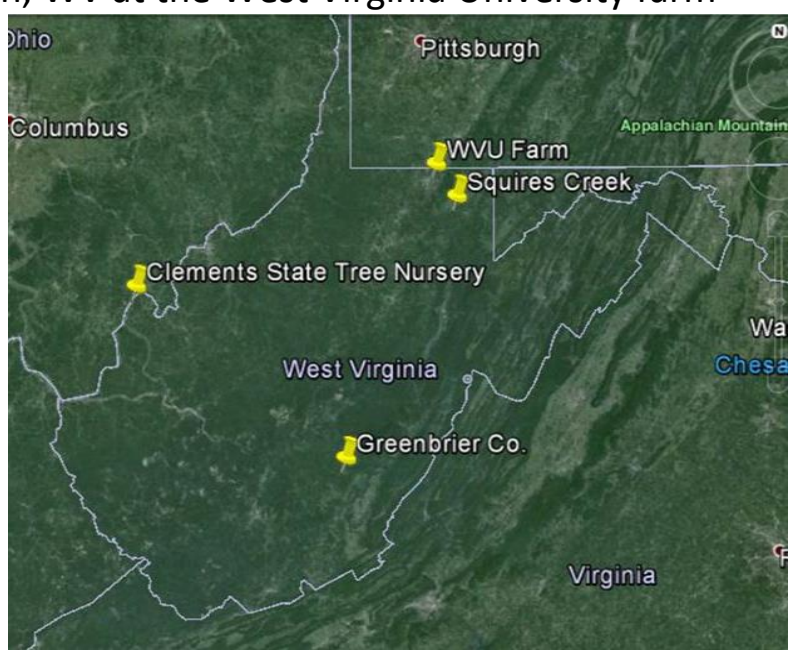

Figure 1. Site map of Salix spp. field trials locations in West Virginia, USA.

$\left(38^{\circ} 57^{\prime} 39.83^{\prime \prime} \mathrm{N}, 82^{\circ} 5^{\prime} 28.58^{\prime \prime} \mathrm{W}\right)$ (Figure 1).

All sites are located within the Appalachian Plateau physiographic region of West

Virginia which is characterized by nearly horizontal sedimentary rocks and dendritic streams.

Mean annual precipitation is similar 40-50 inches in Morgantown, in Preston Co., and in Mason Co., while mean annual precipitation is $50-60$ inches in Greenbrier Co. Likewise, Morgantown, Preston Co., and Mason Co. are all located within USDA Hardiness Zone 6a, while Greenbrier Co. is in the USDA Hardiness Zone $5 b$ due to its colder winter temperatures. 
Table 5. Site characteristics of field trial locations. Field trials were located at the WVU Farm in Monongalia Co., WV, Buck Lilly Surface Mine in Greenbrier Co., WV, Squires Creek No. 1 Mine in Preston Co., WV and Clements State Tree Nursery in Mason Co., WV.

\begin{tabular}{|c|c|c|c|c|}
\hline Site characteristics & WVU Farm & Greenbrier & Squires Creek & Clements \\
\hline Latitude & $39^{\circ} 39^{\prime} 29.55^{\prime \prime N}$ & $38^{\circ} 11^{\prime} 7.31^{\prime \prime} \mathrm{N}$ & $39^{\circ} 28^{\prime} 41.03^{\prime \prime} \mathrm{N}$ & $38^{\circ} 57^{\prime} 39.83^{\prime \prime N}$ \\
\hline Longitude & $79^{\circ} 55^{\prime} 50.17^{\prime \prime} \mathrm{W}$ & $80^{\circ} 35^{\prime} 23.05^{\prime \prime} \mathrm{W}$ & $79^{\circ} 46^{\prime} 59.81^{\prime \prime W}$ & $82^{\circ} 5^{\prime} 28.58^{\prime \prime} \mathrm{W}$ \\
\hline Elevation (ft.) & 1000 & 3650 & 1850 & 575 \\
\hline $\begin{array}{l}\text { Soil Type } \\
\text { Textural Class }\end{array}$ & $\begin{array}{l}\text { Ontario } \\
\text { silt loam }\end{array}$ & $\begin{array}{c}\text { Arnot } \\
\text { loam; clay } \\
\text { loam; silty clay } \\
\text { loam }\end{array}$ & $\begin{array}{l}\text { Gilpin } \\
\text { loam }\end{array}$ & $\begin{array}{l}\text { Hamlin } \\
\text { silt loam }\end{array}$ \\
\hline$\%$ Sand & 18.1 & 25.2 & 29.3 & 26.2 \\
\hline \% Clay & 16.5 & 29.3 & 22.2 & 17.8 \\
\hline$\%$ Silt & 65.4 & 45.5 & 48.5 & 56.1 \\
\hline Aggregate Stability (\%) & 56.7 & 37.1 & 32.2 & 44.3 \\
\hline $\begin{array}{l}\text { Available Water Capacity } \\
(\mathrm{m} / \mathrm{m})\end{array}$ & 0.23 & 0.16 & 0.21 & 0.25 \\
\hline$\%$ Organic Matter & 7.12 & 8 & 5 & 4 \\
\hline $\mathrm{pH}$ & 7.48 & 6.2 & 7.3 & 6.3 \\
\hline Nitrogen ( $\mu \mathrm{gN} /$ gdwsoil/week) & 4.9 & 56 & 9.9 & 5.8 \\
\hline Phosphorus (ppm) & 3.1 & 1 & 1 & 2 \\
\hline Potassium (ppm) & 91.2 & 96.1 & 200.6 & 86.7 \\
\hline Calcium (ppm) & 4671.3 & 1309.2 & 2046.2 & 1611 \\
\hline Aluminum (ppm) & 9.7 & 43 & 29.6 & 17 \\
\hline Magnesium (ppm) & 123.4 & 186.8 & 164.2 & 159.9 \\
\hline Iron (ppm) & 0.5 & 15.7 & 2.2 & 1.7 \\
\hline Manganese (ppm) & 10.7 & 19.7 & 1.4 & 15.9 \\
\hline Zinc (ppm) & 0.5 & 1.9 & 0.7 & 0.5 \\
\hline
\end{tabular}

The soil at the Morgantown location is Ontario silt loam with an elevation of 1000 feet.

The site has $7.12 \%$ organic matter and a $\mathrm{pH}$ of 7.48 . The land was historically farmland and has a severe erosion hazard. Soil at Squire's Creek is rocky, Gilpin loam at an elevation of 1850 feet. The site has $5.0 \%$ organic matter and a $\mathrm{pH}$ of 7.3. The land was historically mined and has been abandoned and sealed since 24 April 1986 and there is a severe erosion hazard. The Greenbrier 
County site is located at the Buck Lilly Surface Mine and is owned by Plum Creek. It is a nonproducing mine and has been classified as such since 12 February 2013. The soil is Arnot loam, clay loam, and silty clay loam at an elevation of 3650 feet with steep slopes and severe erosion potential. The organic matter at this location is highest at $8.0 \%$ and the $\mathrm{pH}$ is 6.2 . Soil at Clements State Tree Nursery is Hamlin silt loam located within the Ohio River floodplain at an elevation of 575 feet. The organic matter at this site is lowest at $4.0 \%$ and the $\mathrm{pH}$ is 6.3 . Erosion is not a strong concern at this location. Aggregate stability is highest at the Morgantown location (56.7\%) followed by Clements (44.3\%), Greenbrier (37.1\%), and Squires Creek (32.2\%). Available water capacity is greatest at Clements $(.25 \mathrm{~m} / \mathrm{m})$ followed by Morgantown $(.23 \mathrm{~m} / \mathrm{m})$, Squires Creek $(.21 \mathrm{~m} / \mathrm{m})$, and Greenbrier $(.16 \mathrm{~m} / \mathrm{m})$.

\section{Source Material}

Willows were obtained from Double A Willow (Fredonia, NY) in the spring of 2013 and stored in a cooler prior to planting. Six varieties of willow were selected for planting: Oneida (S. purpurea x S. miyabeana), SX61 (S. sachalinensis), Marcy (S. sachalinensis x S. miyabeana), Preble (S. viminalis $\times(S$. sachalinensis $\times$ S. miyabeana)), Fish Creek (S. purpurea), and Fabius. Cultivars were selected based on recommendations from Double A Willow and researchers at Cornell University.

The biochar used in this study was obtained from a poultry producer located in the eastern panhandle of West Virginia. The producer installed a fixed bed gasifier in 2007 and biochar is created from poultry litter produced on his farms. Poultry litter biochar is rich in phosphorus and potassium with test runs by the International Biochar Initiative yielding results 
of $1.7-3.2 \% \mathrm{P}$ and $5.4-9.6 \% \mathrm{~K}(2014)$ and test runs by Novak et al. yielding results of $2.94-4.9 \% \mathrm{P}$ (2009).

\section{Field Trial Establishment and Harvest}

The sites were prepared with a pre-treatment of RoundUp ProMax and the dead plant matter and remaining living material was cut back prior to planting. At each site, six $20 \times 20 \mathrm{ft}$. $\left(400 \mathrm{ft}^{2}\right)$ plots were established (Figure 2). A minimum three foot buffer was maintained between plots. Willows were planted by hand using small shovels to create holes with an approximate diameter of 6 inches and an approximate depth of 6 inches ( $\left.170 \mathrm{in}^{3}\right)$. Three plots at each location were selected to receive an application of biochar. Biochar was locally applied at a rate of about 14 tons/acre furrow slice ( $1.5 \%$ or $\sim 31.5$ metric tons/hectare). Within plots, willows were hand planted in four rows with spacing of approximately 18 inches between cuttings, for 48 plants per plot between 21 May 2013 and 28 May 2013. Each plot contained at least four cuttings of each variety. Each cutting was approximately 8 " and the cutting was inserted into the soil so that about two thirds of the cutting was underground. In late June 2013 the plots were weeded and herbicide was applied between rows. Soil samples were collected from all six replicate plots at each site in June 2013 and mean values were calculated from the six samples (Table 5). Samples were collected according to the Cornell Soil Health Protocol (http://soilhealth.cals.cornell.edu). Reports were generated by the Cornell Soil Health Laboratory (Ithaca, NY) and chemical analyses were performed by Diary One testing lab (Ithaca, NY; http://dairyone.com). 

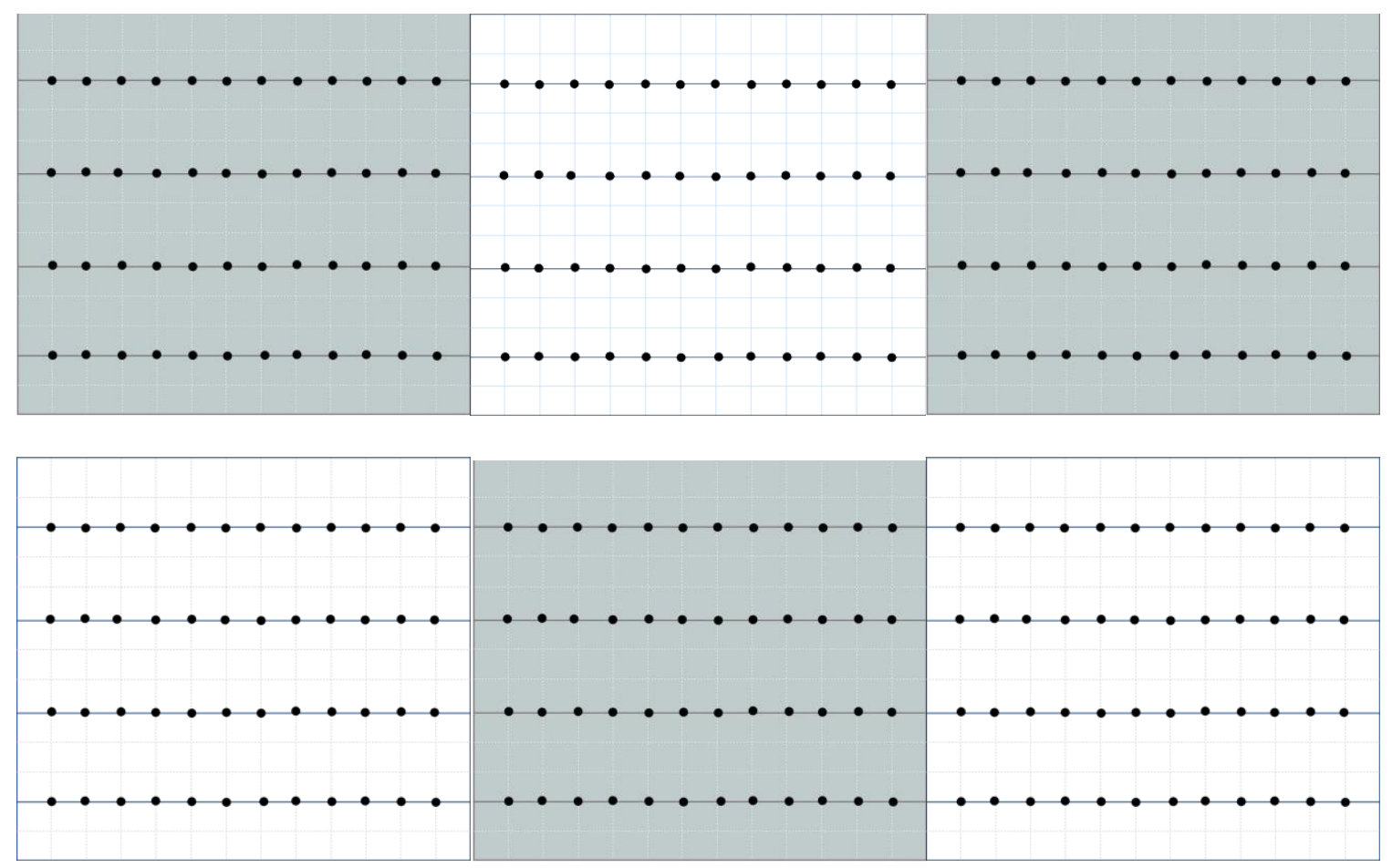

Figure 2. Field trial site and plot layout. Each site consists of 6 plots, 3 of which (grey) receive an application of biochar. Each black dot represents a willow. Four rows of twelve were planted for a total of 48 willows per plot, 288 per site.

\section{Growth and Yield}

Willows were measured for growth and noted for survival then coppiced at the end of the first growing season between December 2013 and March 2014. Growth was measured in the field using the length of the longest stem as a proxy for height. To assess dry biomass yield same variety willows were combined for 6 composite samples for each plot, then oven dried to constant weight at $50^{\circ} \mathrm{C}$ using a Despatch LBB2-18-1 oven. After drying, samples were ground through a $1 \mathrm{~mm}$ screen using a Wiley Mill, Model ED-5.

\section{Thermogravimetric Analysis}

Willow biomass samples were analyzed using a Thermogravimetric Analyzer 701 (Leco Corporation, St. Joseph, MI). Each composite sample was analyzed once. A low volatile, bituminous coal standard (Alberta, Canada) was used for quality assurance (Leco Corporation, 
St. Joseph, MI). Data collected from this analysis include fixed carbon, ash, volatile matter, and moisture content as a percentage of total dry biomass. The method used was ASTM D7852 MVA in Coal.

\section{Elemental Analysis}

Ultimate analysis was performed using a Perkin Elmer 2400 Series II CHNS/O Analyzer

(Perkin Elmer Inc., Shelton, CT). Samples were weighed using an AD 6 Autobalance Controller (Perkin Elmer Inc., Shelton, CT) and data was recorded using EA 2400 Data Manger Version 1.0.0088 software (Perkin Elmer Inc., Shelton, CT). Each composite sample was analyzed once. Traits obtained from this analysis were percent carbon, hydrogen, nitrogen, and sulfur as a proportion of total biomass.

\section{Heating Value}

Heating value of the samples was determined using a Parr 6300 Bomb Calorimeter (Moline, IL). Each composite sample was analyzed once. Data collected from this analysis include BTU/Ib.

\section{Statistical Analysis}

The examination of the willow samples included thirteen split-plot analyses of variance using randomized blocks. These were broken down into several categories of response variables. The first category includes mortality, growth and yield. The second includes a thermogravimetric analysis which provides data on wood composition including ash, fixed carbon, volatile matter, and moisture content. A third category provided data on an elemental analysis and includes hydrogen, nitrogen, oxygen, sulfur, and carbon. Finally, heating value was analyzed for BTU/lb. Site type (SiteType), either agricultural or reclaimed mine land, was a 
method of randomized design testing and the main plot experimental factor. The completely randomized sub-plot experimental factors was biochar (BC) (biochar amended or control), and the sub-sub-plot experimental factors were variety (VAR) (one of the six cultivars listed in the materials and methods section). A summary of the analyses and significant response variables can be viewed in Table 6.

All statistical analyses were performed using SAS version 9.3 at a critical $\alpha$ level of 0.05 . All statistical analyses for variables were performed using a split-split-plot factorial design, ANOVA using site type (agricultural or reclaimed mine) for the main plot, treatment (biochar amended or reference) for the sub plot, and willow variety as the sub-sub plot. A split-split-plot factorial layout design was appropriate because the three different effects (site type, treatment, and variety) had experimental units of varying sizes.

Mortality analysis was done using the frequency procedure, growth and yield analyses used mixed procedure, and thermogravimetric, elemental, and heating value analyses were done using Glimmix procedure. The frequency procedure is a frequency distribution for categorical data values. It analyzes categorical data based on cell frequency. The mixed procedure fits a variety of mixed linear models to data and uses these to make statistical inferences about the data. It assumes normal distribution and that the means are linear. The glimmix procedure is used for both normal and non-normal data with correlations or nonconstant variability for non-Gaussian distribution. Glimmix stands from generalized linear mixed models. This allows for non-normal data and random effects, as well as correlations amongst responses. 
Table 6. Response variables of interest analyzed in this study. This table shows the various analyses performed on samples, a description of the variable, which response variables were statistically significant at $\alpha=0.05$ level and the corresponding P Value. Var=Variety/Cultivar; BC=Biochar amended plots.

\begin{tabular}{|c|c|c|c|}
\hline Name & Description & $\begin{array}{l}\text { Response } \\
\text { Variable }\end{array}$ & P Value \\
\hline \multirow{2}{*}{ Mortality } & \multirow{2}{*}{$\begin{array}{l}\text { Count and } \% \text { of dead } \\
\text { plants after year } 1\end{array}$} & SiteType & $<0.0001$ \\
\hline & & Cult & 0.0037 \\
\hline \multirow{2}{*}{ Growth } & \multirow{2}{*}{$\begin{array}{l}\text { Height }(\mathrm{cm}) \text { after } 1 \\
\text { year's growing season }\end{array}$} & $\mathrm{BC}$ & 0.0003 \\
\hline & & Var & 0.0569 \\
\hline \multirow{3}{*}{ Yield } & \multirow{3}{*}{$\begin{array}{l}\text { Mass }(\mathrm{g}) \text { of year } 1 \\
\text { biomass }\end{array}$} & $\mathrm{BC}$ & 0.0180 \\
\hline & & Var & 0.0046 \\
\hline & & SiteType*BC*Var & 0.0216 \\
\hline Ash & $\begin{array}{l}\% \text { weight of ash in year } \\
1 \text { samples }\end{array}$ & SiteType*BC*Var & 0.0235 \\
\hline Fixed Carbon & $\begin{array}{l}\% \text { weight of fixed } \\
\text { carbon in year } 1 \\
\text { samples }\end{array}$ & Var & 0.0148 \\
\hline Volatile Matter & $\begin{array}{l}\% \text { weight of volatile } \\
\text { matter in year } 1 \\
\text { samples }\end{array}$ & SiteType*BC*Var & 0.0294 \\
\hline $\begin{array}{l}\text { Moisture } \\
\text { Content }\end{array}$ & $\begin{array}{l}\% \text { weight of moisture in } \\
\text { year } 1 \text { samples }\end{array}$ & ---- & ----- \\
\hline Hydrogen & $\begin{array}{l}\% \text { weight of hydrogen } \\
\text { in year } 1 \text { samples }\end{array}$ & ---- & ----- \\
\hline \multirow{3}{*}{ Nitrogen } & \multirow{3}{*}{$\begin{array}{c}\% \text { weight of nitrogen in } \\
\text { year } 1 \text { samples }\end{array}$} & BC & 0.0056 \\
\hline & & SiteType*BC & 0.0259 \\
\hline & & Var & 0.0385 \\
\hline Sulfur & $\begin{array}{l}\% \text { weight of sulfur in } \\
\text { year } 1 \text { samples }\end{array}$ & ---- & ---- \\
\hline Oxygen & $\begin{array}{l}\% \text { weight of oxygen in } \\
\text { year } 1 \text { samples }\end{array}$ & ---- & ---- \\
\hline Carbon & $\begin{array}{l}\% \text { weight of carbon in } \\
\text { year } 1 \text { samples }\end{array}$ & ---- & ---- \\
\hline Heating Value & $\begin{array}{l}\text { The heating value of } \\
\text { year } 1 \text { samples in } \\
\text { BTU/lb }\end{array}$ & Var & 0.0045 \\
\hline
\end{tabular}




\section{Chapter 4}

\section{Results and Discussion}

\section{Mortality}

Across all sites and cultivars, mortality was at $47.7 \%$ at the end of the growing season.

Mortality was lowest at site Greenbrier (32.1\%) followed by Squires Creek (46.1\%), and Clements (64.8\%) (Figure 3). Mortality data was not collected for the WVU Farm site. Pearson's chi squared test revealed a significant differences in mortality by site $(P<0.0001)($ Table 7$)$. For a summary of mortality data, Table 8 shows a count of survivorship for each site and cultivar as well as minimum and maximum survivorship by site, cultivar, and treatment.

Significant differences in mortality were observed between cultivars $(P<0.0037)$ (Table 9). Cultivar 'Oneida' (ONE) demonstrated the least mortality with $67.2 \%$ surviving $(P<0.0164)$. Cultivars 'Marcy' (MAR) and 'Preble' (PRE) performed poorest with $46.0 \%(P<0.0059)$ and $45.6 \%$ $(\mathrm{P}<0.0047)$ survivorship, respectively (Figure 4). For all six genotypes planted at the 3 sites in 2013, survivorship was below the predicted $90 \%$ survivorship provided by Double A Willow (Fredonia, NY). Survivorship was highest at site 'Greenbrier' potentially due to the unique conditions at this site including a lower mean average temperature, a slightly higher annual rainfall, and a higher nitrogen content than the other sites. Site 'Greenbrier' may more closely resemble the geographic origin of the cuttings thereby resulting in lower mortality at that particular site however due to the significant number of environmental variables it is extremely difficult to attribute mortality to any of these factors. 
Table 7. ANOVA table for mortality of Salix spp. by site for three field trial sites in West Virginia. A significant effect was observed using Pearson's chi squared test $(P<0.0001)$.

\begin{tabular}{lrcr}
\multicolumn{1}{c}{ N } & \multicolumn{1}{c}{ DF } & -LogLike & RSquare (U) \\
\hline 860 & 2 & 31.595628 & 0.0531 \\
& & & \\
\multicolumn{1}{c}{ Test } & ChiSquare & Prob $>$ ChiSq & \\
\hline $\begin{array}{l}\text { Likelihood } \\
\text { Ratio }\end{array}$ & 63.191 & $<.0001^{*}$ & \\
Pearson & 62.106 & $<.0001^{*}$
\end{tabular}

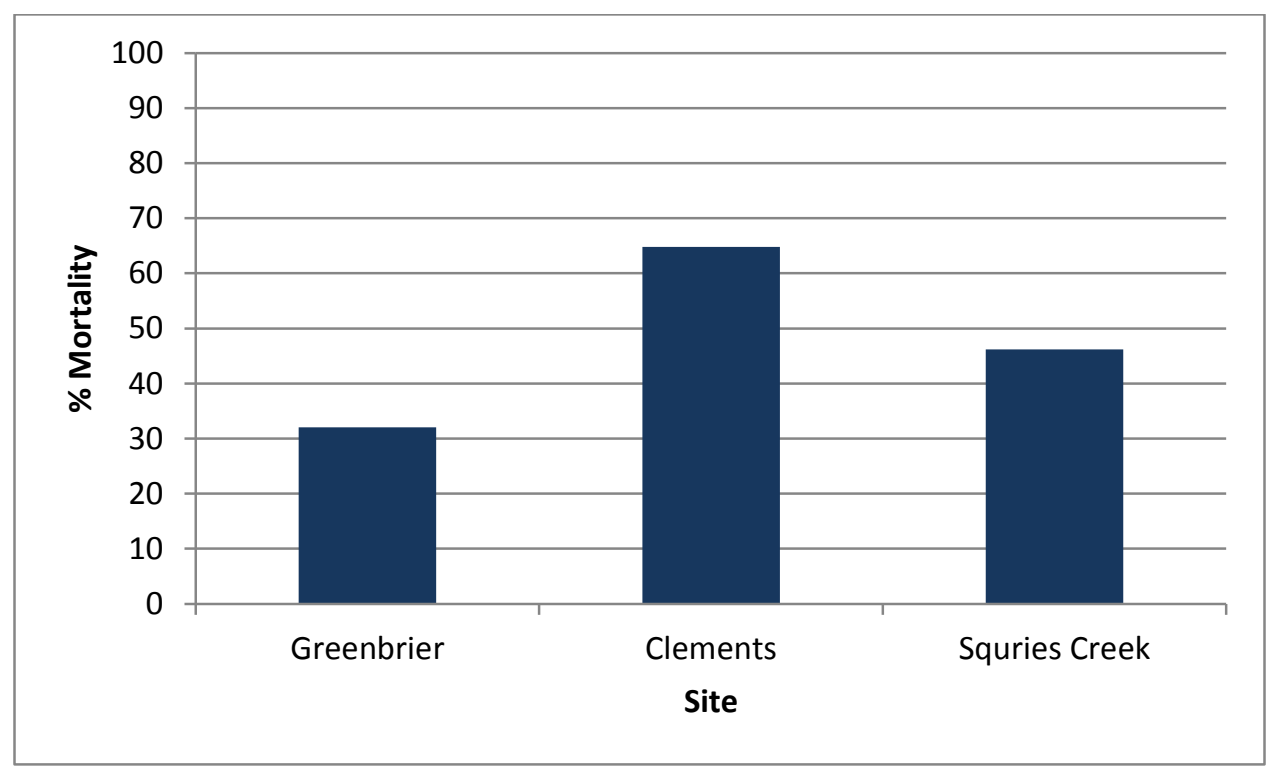

Figure 3. Mortality (\%) of Salix spp. by site for three field trial sites in West Virginia. Site 'Clements' had the greatest mortality and a significant mortality by site effect was observed $(P<0.0001)$. 
Table 8. Count of survivorship of Salix spp. for each treatment, cultivar, and site of field trials in West Virginia. Maximum and minimum survivorship by site, treatment (REF=non-biochar amended; $B C=$ biochar amended), and cultivar are also shown.

\begin{tabular}{|c|c|c|c|c|c|c|c|c|c|c|}
\hline \multirow[b]{2}{*}{ Cultivar } & $\begin{array}{l}\text { Treatme } \\
\text { Site } \\
\text { CLEMEN }\end{array}$ & $\begin{array}{l}\text { nt by } \\
\text { is }\end{array}$ & & GREEN & BRIER & & SQUIRES & & & \\
\hline & REF & BC & $\begin{array}{l}\text { CLEMENTS } \\
\text { Total }\end{array}$ & REF & BC & $\begin{array}{l}\text { GREENBRIER } \\
\text { Total }\end{array}$ & REF & BC & $\begin{array}{l}\text { SQUIRES } \\
\text { Total }\end{array}$ & $\begin{array}{l}\text { Grand } \\
\text { Total }\end{array}$ \\
\hline \multicolumn{11}{|l|}{ MAR } \\
\hline No. Surviving & 19 & 22 & 41 & 27 & 28 & 55 & 19 & 24 & 43 & 139 \\
\hline Minimum & 4 & 8 & 4 & 11 & 6 & 6 & 9 & 9 & 9 & 4 \\
\hline Maximum & 15 & 14 & 15 & 16 & 22 & 22 & 10 & 15 & 15 & 22 \\
\hline Standard Deviation & 7.78 & 4.24 & 5.19 & 3.54 & 11.31 & 6.85 & 0.71 & 4.24 & 2.87 & 5.00 \\
\hline \multicolumn{11}{|l|}{ FAB } \\
\hline No. Surviving & 20 & 24 & 44 & 23 & 22 & 45 & 29 & 33 & 62 & 151 \\
\hline Minimum & 9 & 7 & 7 & 9 & 6 & 6 & 11 & 16 & 11 & 6 \\
\hline Maximum & 11 & 17 & 17 & 14 & 16 & 16 & 18 & 17 & 18 & 18 \\
\hline Standard Deviation & 1.41 & 7.07 & 4.32 & 3.54 & 7.07 & 4.57 & 4.95 & 0.71 & 3.11 & 4.25 \\
\hline \multicolumn{11}{|l|}{ FC } \\
\hline No. Surviving & 36 & 31 & 67 & 23 & 19 & 42 & 26 & 16 & 42 & 151 \\
\hline Minimum & 11 & 5 & 5 & 5 & 1 & 1 & 12 & 8 & 8 & 1 \\
\hline Maximum & 25 & 26 & 26 & 18 & 18 & 18 & 14 & 8 & 14 & 26 \\
\hline Standard Deviation & 9.90 & 14.85 & 10.40 & 9.19 & 12.02 & 8.81 & 1.41 & 0 & 3.00 & 7.91 \\
\hline \multicolumn{11}{|l|}{ ONE } \\
\hline No. Surviving & 27 & 18 & 45 & 25 & 25 & 50 & 16 & 26 & 42 & 137 \\
\hline Minimum & 5 & 6 & 5 & 12 & 4 & 4 & 6 & 12 & 6 & 4 \\
\hline Maximum & 22 & 12 & 22 & 13 & 21 & 21 & 10 & 14 & 14 & 22 \\
\hline Standard Deviation & 12.02 & 4.24 & 7.80 & 0.71 & 12.02 & 6.95 & 2.83 & 1.41 & 3.42 & 5.81 \\
\hline \multicolumn{11}{|l|}{ PRE } \\
\hline No. Surviving & 14 & 33 & 47 & 25 & 16 & 41 & 24 & 13 & 37 & 125 \\
\hline Minimum & 1 & 7 & 1 & 11 & 2 & 2 & 7 & 6 & 6 & 1 \\
\hline
\end{tabular}




\begin{tabular}{|c|c|c|c|c|c|c|c|c|c|c|}
\hline Maximum & 13 & 26 & 26 & 14 & 14 & 14 & 17 & 7 & 17 & 26 \\
\hline Standard Deviation & 8.49 & 13.44 & 10.69 & 2.12 & 8.49 & 5.68 & 7.07 & 0.71 & 5.19 & 6.96 \\
\hline \multicolumn{11}{|l|}{ SX61 } \\
\hline No. Surviving & 22 & 21 & 43 & 20 & 34 & 54 & 30 & 30 & 60 & 157 \\
\hline Minimum & 4 & 9 & 4 & 9 & 6 & 6 & 14 & 13 & 13 & 4 \\
\hline Maximum & 18 & 12 & 18 & 11 & 28 & 28 & 16 & 17 & 17 & 28 \\
\hline Standard Deviation & 9.90 & 2.12 & 5.85 & 1.41 & 15.56 & 9.88 & 1.41 & 2.83 & 1.83 & 6.35 \\
\hline Total No. Surviving & 138 & 149 & 287 & 143 & 144 & 287 & 144 & 142 & 286 & 860 \\
\hline
\end{tabular}


Variety 'Oneida' had highest survivorship of all cultivars. 'Oneida' is a cultivar which has demonstrated low incidence of rust disease, mammal browsing, or damage by beetle or sawfly in yield trials (Cameron et al., 2007).

Table 9. ANOVA table for mortality of Salix spp. by cultivar across all field trial sites in West Virginia. A significance difference was observed using Pearson's chi squared test $(P<0.0037)$.

\begin{tabular}{lrrr}
\multicolumn{1}{c}{ N } & \multicolumn{1}{c}{ DF } & \multicolumn{1}{c}{-LogLike } & \multicolumn{1}{c}{$\begin{array}{c}\text { RSquare } \\
\text { (U) }\end{array}$} \\
\hline \multicolumn{1}{c}{860} & 5 & 8.8876342 & 0.0149 \\
& & & \\
\multicolumn{1}{c}{ Test } & ChiSquare & Prob $>$ ChiSq & \\
\hline $\begin{array}{l}\text { Likelihood } \\
\text { Ratio }\end{array}$ & 17.775 & $0.0032^{*}$ & \\
Pearson & 17.478 & $0.0037^{*}$ &
\end{tabular}

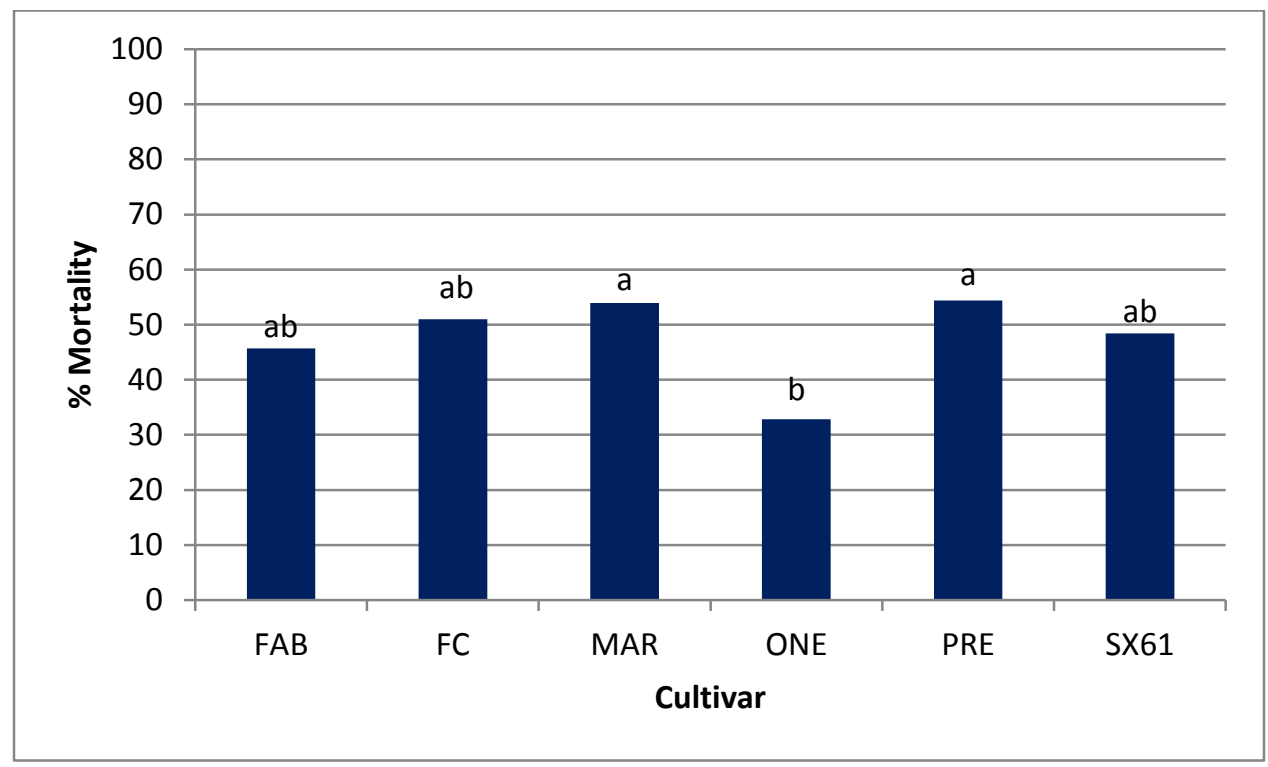

Figure 4. Mortality of Salix spp.by cultivar for all field trial sites in West Virginia. A significant cultivar effect was observed $(P<0.0037)$. Cultivar 'Oneida' showed significant differences from cultivars 'Preble' $(P<0.0059)$ and 'Marcy' $(\mathrm{P}<0.0047)$ 


\section{Growth and Yield}

Biochar amended plots produced greater growth and yield than reference plots. While first year growth and yield are not indicative of the growth and yield potential of the rotation, the increased growth and yield in treatment plots may indicate a competitive advantage over weeds (Abrahamson et al., 2010). Moreover, overall growth and yield were highest at 'Greenbrier'. Greenbrier was one of two sites with a $\mathrm{pH}$ within the optimal range for shrub willow cultivation.

\section{Growth}

Average height growth regardless of site, cultivar, or treatment was $41.4 \mathrm{~cm}$. A statistically significant effect for growth by treatment was observed ( $P=0.0003)$ (Table 10 ; Figure 5) with plants in the biochar amended plots growing on average $53.3 \mathrm{~cm} \pm 3.8 \mathrm{~cm}$ and plants in reference plots growing on average $29.5 \mathrm{~cm} \pm 3.6 \mathrm{~cm}$.

A trend towards a significant cultivar effect was observed $(P=0.0659)$. Variety 'Fish Creek' demonstrated the highest average growth $(51.6 \mathrm{~cm})$ followed closely by 'SX61' $(50.3$ $\mathrm{cm})$. Varieties 'Oneida' and 'Preble' had the lowest average growth of $31.5 \mathrm{~cm}$ and $33.5 \mathrm{~cm}$ respectively. The majority of cultivars exhibited highest growth at site 'Greenbrier,' however varieties 'Fish Creek' and 'Oneida' had the highest growth at the 'Morgantown' site. Unlike the other four cultivars, these two varieties are S. purpurea or its hybrids. Differences in hybrid vigor may explain the observed differences in growth. 
Table 10. ANOVA table for height growth of Salix spp. at four field trial sites in West Virginia. Significant effect was observed for biochar $(P=0.0003)$.

\begin{tabular}{lrrrr} 
Effect & Num DF & \multicolumn{1}{l}{ Den DF } & F Value & Pr $>$ F \\
\hline SiteType & 1 & 14 & 0 & 0.9943 \\
BC & 1 & 14 & 23.02 & 0.0003 \\
SiteType*BC & 1 & 14 & 0.08 & 0.7863 \\
Var & 5 & 34 & 2.31 & 0.0659 \\
SiteType*Var & 5 & 34 & 1.84 & 0.1319 \\
BC*Var & 5 & 24 & 2.38 & 0.0684 \\
SiteType*BC*Var & 5 & 24 & 2.33 & 0.0738
\end{tabular}

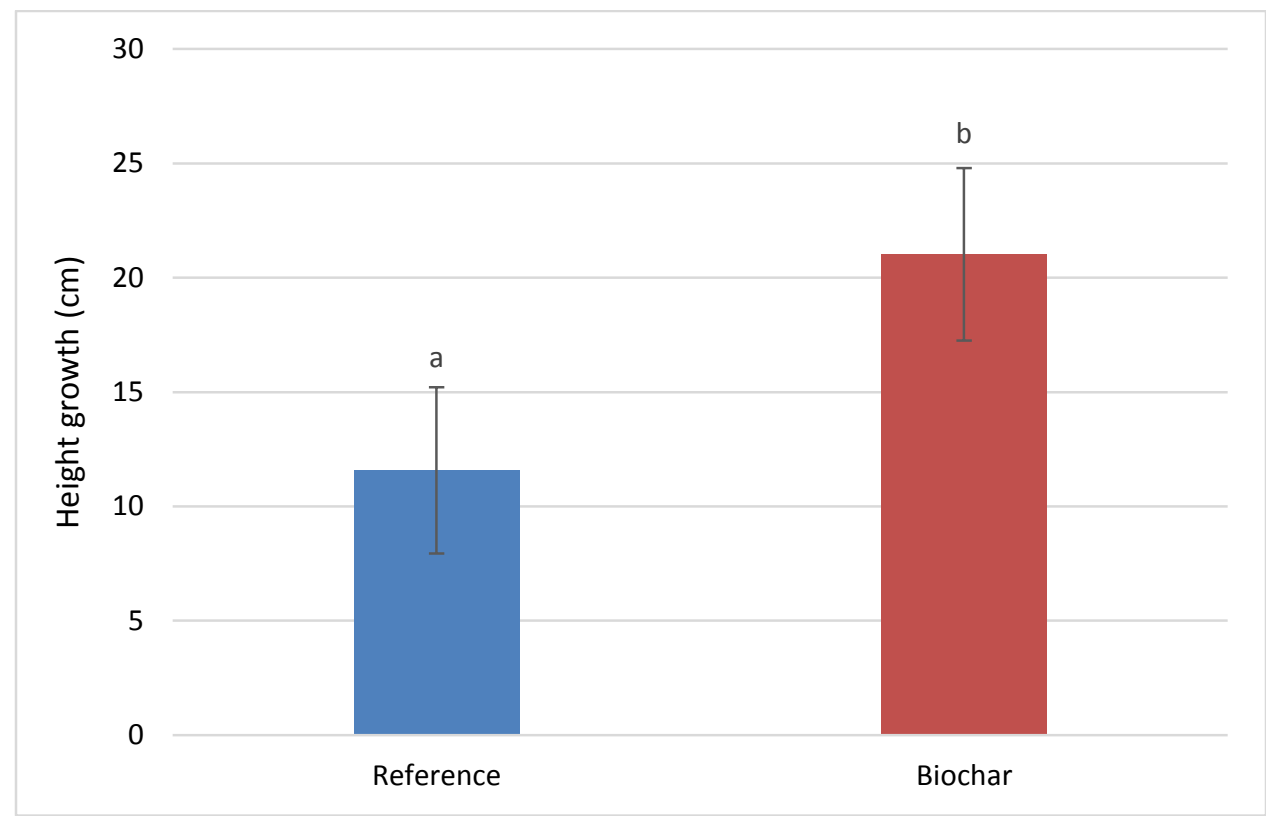

Figure 5. Height growth by treatment for Salix spp. at four field trial sites in West Virginia. A significant difference of growth by treatment was observed $(P=0.0003)$.

\section{Yield}

Average yield regardless of site, treatment, or variety was $3.8 \mathrm{~kg} / \mathrm{acre}$. Biochar amended plots yielded an average of $5.0 \mathrm{~kg} /$ acre which was significantly higher than reference plots which yielded $2.9 \mathrm{~kg} / \mathrm{acre}(\mathrm{P}=0.0180)$ (Figure 6; Table 11).

Additionally, a significant variety effect was observed ( $P=0.0046)$ (Table 11). Pairwise comparisons indicate that cultivar 'Fabius' performed better than all other cultivars with the exception of cultivar 'Preble'. Furthermore, a significant site type by biochar by variety effect was observed $(P=0.0216)$ (Table 11). For four of the six varieties examined, yield was highest at 
Greenbrier ('Fabius,' 'Marcy,' 'Preble,' and 'SX61'). The remaining two varieties ('Fish Creek' and 'Oneida') performed best at the Morgantown site. Varieties 'Oneida' and 'Marcy' had higher yields in biochar amended plots at reclaimed mine sites and higher yields in reference plots at agricultural sites (Figure 6). This indicates that biochar may have been more effective at retaining water or essential nutrients for plant growth in depleted soils, while agricultural sites may be more saturated with nutrients thus biochar having a less significant effect.

Table 11. ANOVA table for yield of Salix spp. at field trial sites in West Virginia. Significant effects were observed for the interaction of site type, treatment, and variety $(P=0.0216)$, variety $(P=0.0046)$, and treatment $(P=0.0180)$.

\begin{tabular}{lrrrr} 
Effect & Num DF & Den DF & F Value & Pr $>$ F \\
\hline SiteType & 1 & 20 & 0.07 & 0.792 \\
BC & 1 & 20 & 6.65 & 0.018 \\
SiteType*BC & 1 & 20 & 0.73 & 0.4028 \\
Var & 5 & 50 & 3.91 & 0.0046 \\
SiteType*Var & 5 & 50 & 1.6 & 0.1786 \\
BC*Var & 5 & 39 & 0.63 & 0.6755 \\
SiteType*BC*Var & 5 & 39 & 3.01 & 0.0216
\end{tabular}




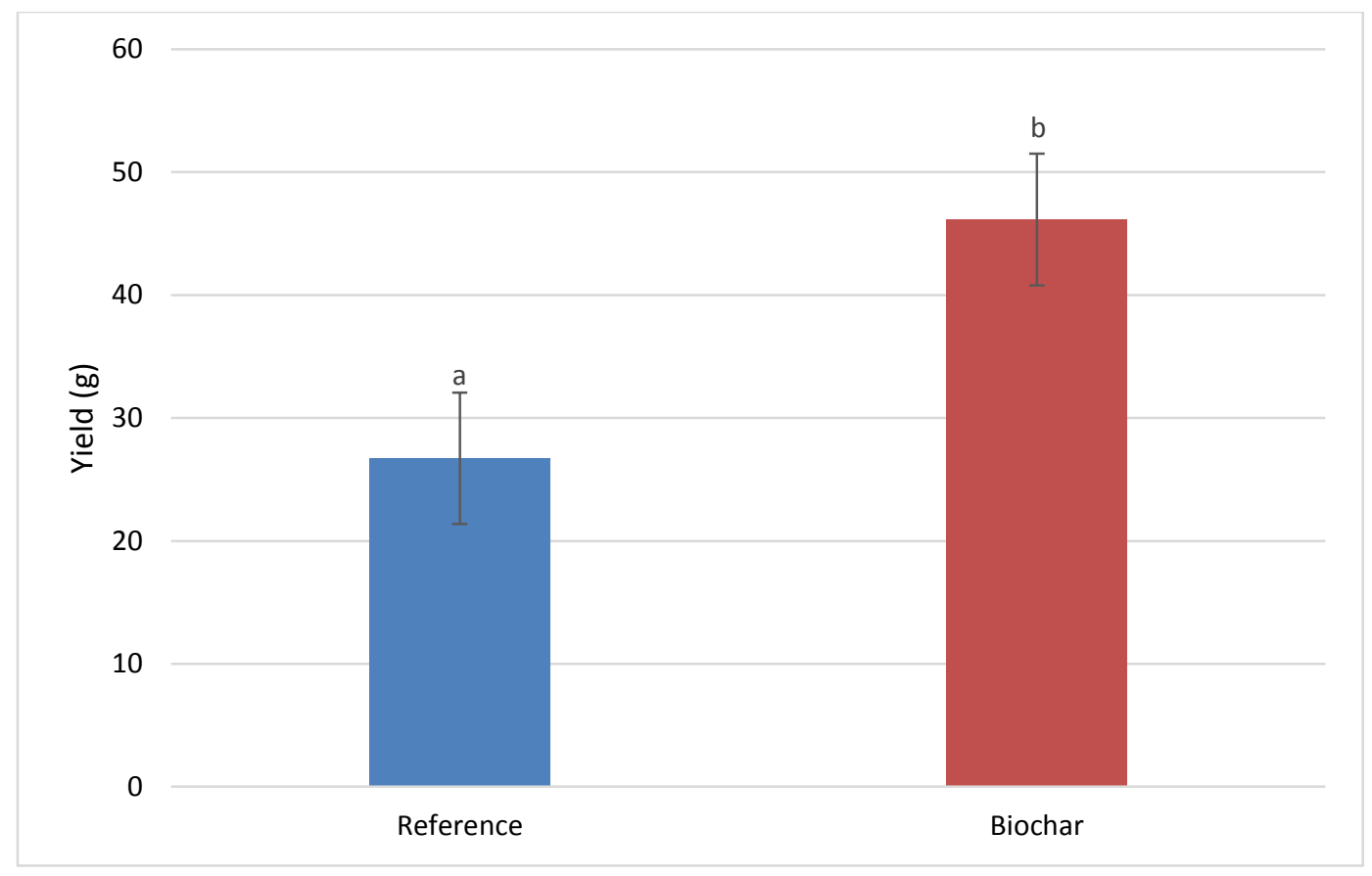

Figure 6. Yield of Salix spp. by treatment and field trial site in West Virginia. Biochar amended plots had statistically significantly higher yield than reference plots at all sites $(P=0.0180)$.

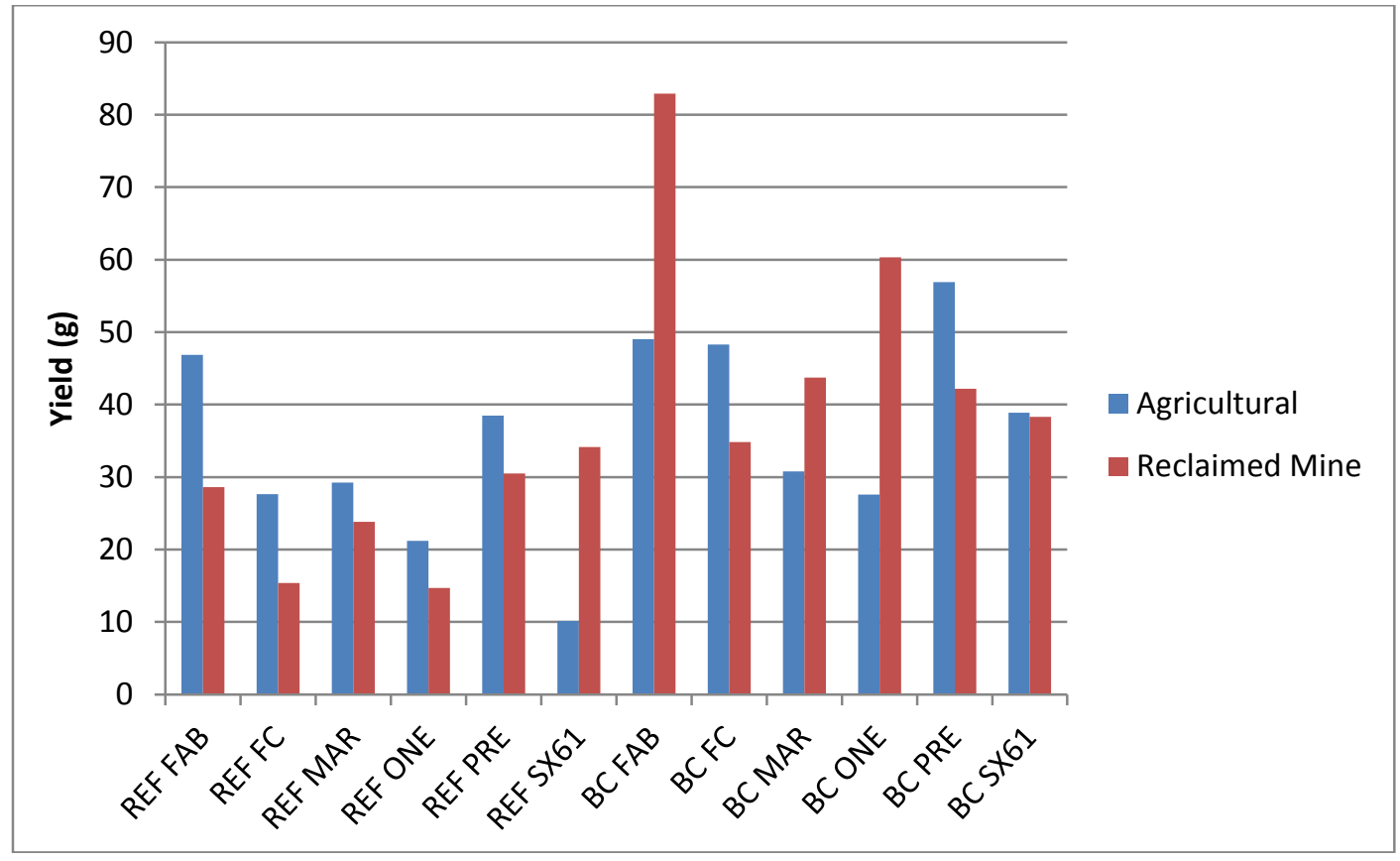

Figure 7. A significant site by biochar by variety effect for yield $(P=0.0216)$ of Salix spp. at field trial sites in West Virginia. Due to the complex interaction of biochar, soils/site type, and variety, different varieties performed better on reclaimed mine sites than agricultural sites and/or in the absence of biochar. 


\section{Thermogravimetric Analysis of Biomass Composition}

Variation was expected to be high in the wood physical properties of the shrub willow varieties due to the intentional maintenance of genetic variation among cultivars.

\section{Ash Content}

Average ash content did not differ significantly by site type and average ash content for all sites was $2.7 \%$ by weight. This is higher than the general guideline of $1 \%$ ash by weight for woody biomass (McKendry, 2002). Ash content in this study was most similar to two New York studies (Serapiglia et al., 2013; Tharakan et al., 2003). Serapiglia et al. report ash content to be $<3 \%$ of the total biomass for all cultivars. All samples in this study demonstrated higher ash content than their counterparts in the Serapiglia et al. study. Field trials indicating lower ash contents were mainly conducted in Europe. The higher ash content may also be explained by the age of the samples. Samples are generally analyzed for ash content at the end of a rotation (3-4 years) meanwhile the samples in this study were analyzed after year one. A higher proportion of bark to wood has been associated with higher ash content thereby explaining the relatively high ash content of these samples.

Variety 'Oneida' showed differential response to biochar treatment between agricultural sites and reclaimed mine sites $(\mathrm{P}<0.0235)($ Table 12$)$. The significant interaction between these variables is due to variety 'Oneida' having a lower ash content in agricultural site types in the biochar amended plots and a higher ash content in agricultural site types for reference plots (Figure 8). Serapiglia et al., hypothesize that ash content is related to nutrient content in the soil. Agricultural soils had much higher average calcium content (3141.5 ppm) compared to reclaimed mine soils (1677.7 ppm) as well as much lower average aluminum content than reclaimed mine sites (13.3ppm and 36.3ppm, respectively). Additionally, magnesium, iron, and 
zinc were higher at agricultural sites than reclaimed mine sites. Since nutrient concentrations were higher at agricultural sites than reclaimed mine sites, the biochar was more effective in increasing nutrient availability at reclaimed mine sites, thereby increasing ash content in treatment plots whereas biochar in agricultural sites did not drastically increase nutrient availability.

Table 12. ANOVA table for ash content of Salix spp. field trials in West Virgnina. A significant site type $x$ treatment $x$ variety effect was observed $(P=0.0235)$

\begin{tabular}{lrrrr} 
Effect & Num DF & Den DF & F Value & Pr $>$ F \\
\hline SiteType & 1 & 20.52 & 3.09 & 0.0939 \\
BC & 1 & 20.52 & 0.42 & 0.5241 \\
SiteType*BC & 1 & 20.52 & 0.04 & 0.849 \\
Var & 5 & 85.82 & 1.29 & 0.275 \\
SiteType*Var & 5 & 85.82 & 0.26 & 0.9361 \\
BC*Var & 5 & 85.82 & 1.69 & 0.1453 \\
SiteType*BC*Var & 5 & 85.82 & 2.75 & 0.0235
\end{tabular}




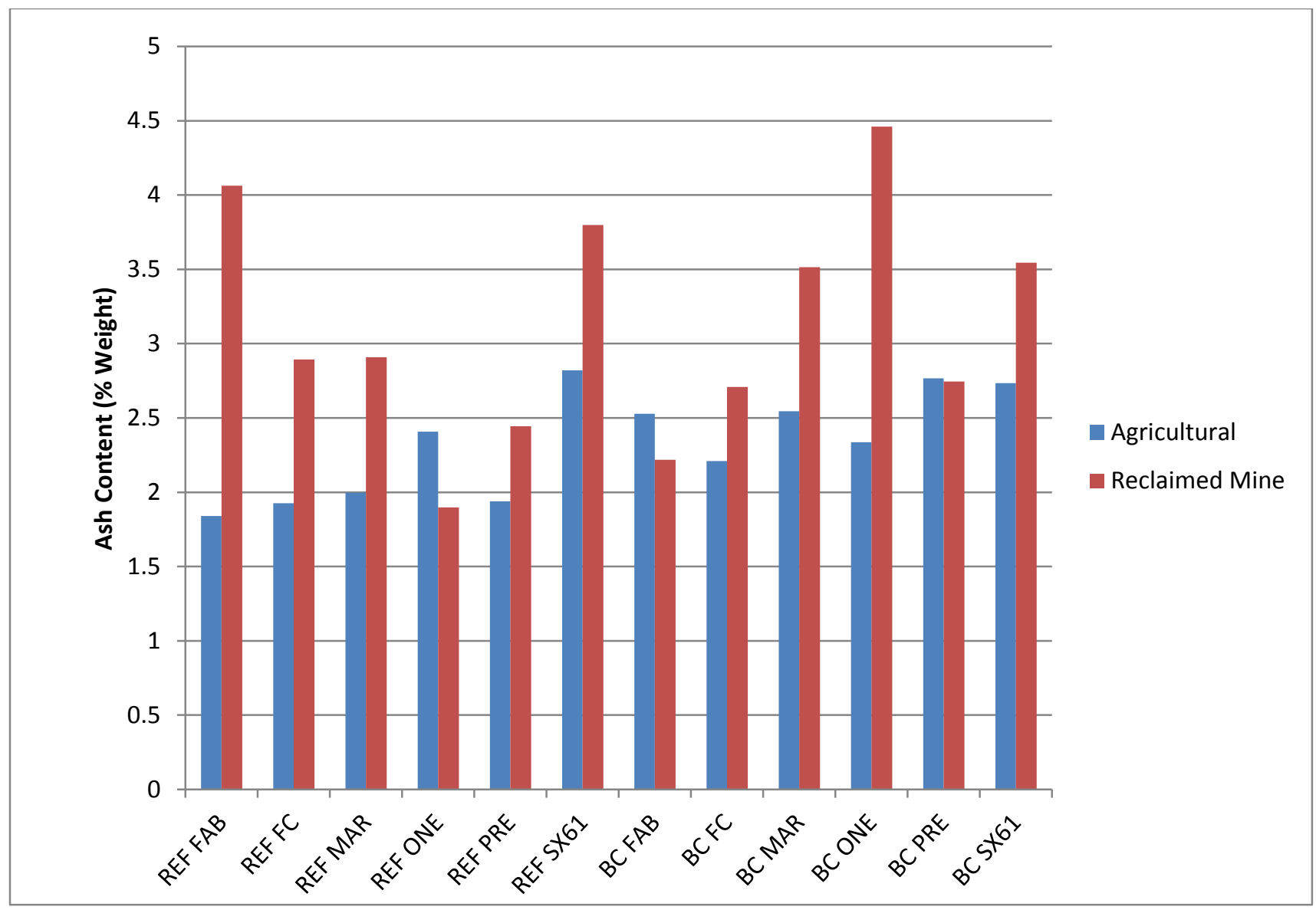

Figure 8. A significant site type by biochar by variety interactions was observed for ash content $(P<0.0235)$ of Salix spp. at field trial sites in West Virginia. This is due to variety 'Oneida' having a lower ash content in agricultural site types in the biochar amended plots and a higher ash content in agricultural site types for reference plots. Average ash content is displayed in percent weight with standard error bars.

\section{Fixed Carbon}

The average fixed carbon regardless of site type, variety, or treatment was $17.5 \%$ by weight, slightly higher than the $17 \%$ general guideline provided by Demirbas (2004). Significant fixed effects for fixed carbon were observed for variety $(P<0.0148)$ (Table 13; Figure 9). Variety 'Fabius' was greatest with $18.1 \%$ fixed carbon by percent weight while varieties 'Marcy' and 'SX61' were lowest with $16.9 \%$ and $17.0 \%$ fixed carbon, respectively. In a least squares means analysis, cultivar 'Fabius' was significantly different from 'Marcy' at $\alpha=0.05$ level $(P<0.0280)$ and there was a trend towards a significant difference with' SX61' $(P<0.0585)$ however no other 
trends were observed between varieties. Furthermore, no trends were observed for other fixed effects.

Varieties 'SX61' and 'Marcy' are both cultivars of S. sachalinensis, while 'Fabius' is a cultivar of S. viminalis x S. miyabeana. Hybrid differences may account for the differences observed between these cultivars. Carbon is considered an extremely important property because it directly influences heating value. Cultivars 'SX61' and 'Marcy' may be considered for exclusion from these sites due to their low carbon content and therefore lower quality as a fuel feedstock.

Table 13. ANOVA table for fixed carbon content of Salix spp. at field trial sites in West Virginia. A significant variety effect was observed ( $P=0.0148)$.

\begin{tabular}{lrrrr} 
Effect & Num DF & \multicolumn{1}{c}{ Den DF } & \multicolumn{1}{l}{ F Value } & Pr $>$ F \\
\hline SiteType & 1 & 20 & 1.31 & 0.2665 \\
BC & 1 & 20 & 1.33 & 0.2622 \\
SiteType*BC & 1 & 20 & 1.82 & 0.1927 \\
Var & 5 & 47 & 3.18 & 0.0148 \\
SiteType*Var & 5 & 47 & 0.93 & 0.4692 \\
BC*Var & 5 & 37 & 0.26 & 0.9334 \\
SiteType*BC*Var & 5 & 37 & 0.64 & 0.6708
\end{tabular}




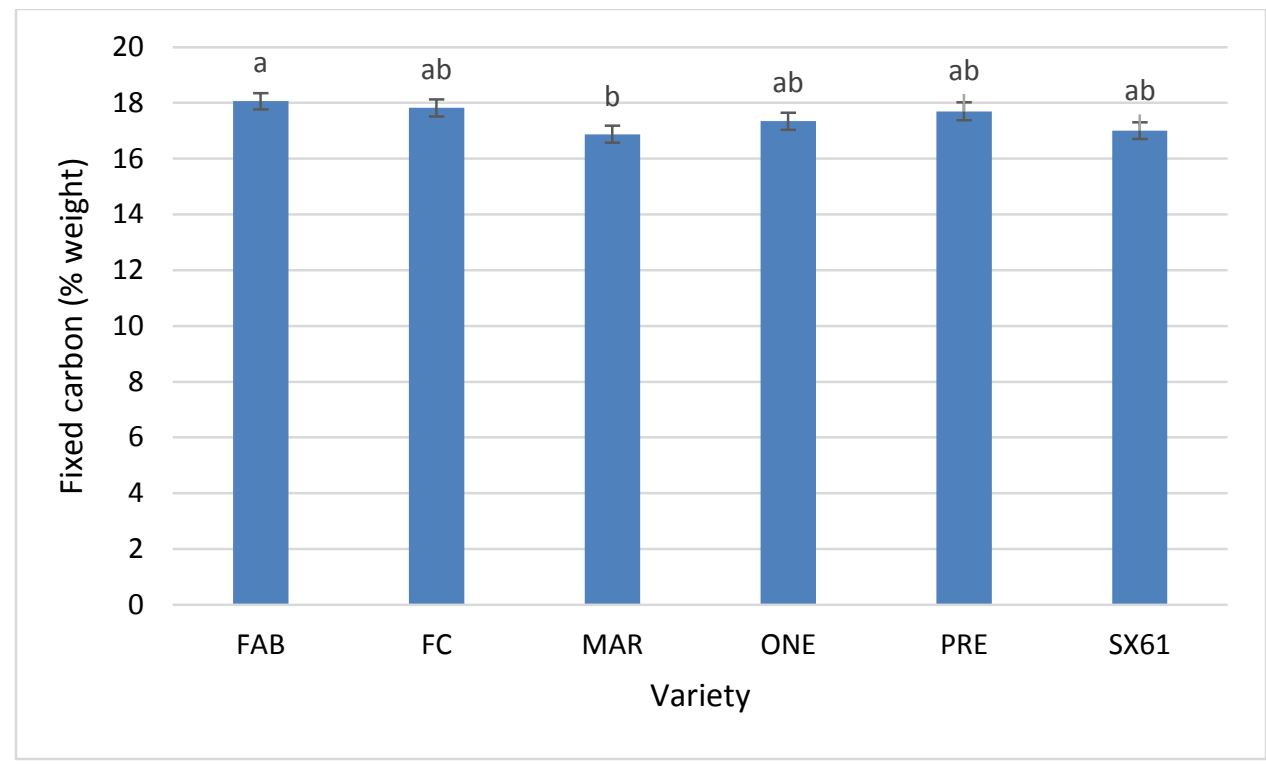

Figure 9. Fixed carbon (\% weight) content of Salix spp. by variety observed in field trials in West Virginia. A significant effect is observed $(P<0.0148)$.

\section{Volatile Matter}

Volatile matter content averaged $79.8 \%$ by weight for all samples. Volatile matter content in willows in this study was lower than the general guideline of $82 \%$ for woody biomass. These sites and cultivars are suitable for shrub willow cultivation based on this standard in that lower volatile matter is better suited to combustion systems.

Composition of volatile matter was significant solely in the interaction between site type, biochar, and variety $(P<0.0294)$ (Table 14). The significant interaction between these variables is due to variety 'Oneida' having a lower volatile matter content in agricultural site types in the biochar amended plots and a higher volatile matter content in agricultural site types for reference plots (Figure 10). Additionally, varieties 'Fabius' and 'SX61' showed a higher volatile matter contents in agricultural site types for biochar amended plots and lower volatile matter content in agricultural site types for reference plots (Figure 10). 
Table 14. ANOVA table for volatile matter content of Salix spp. samples from field trials in West Virginia. A significant effect was observed for the site type by biochar by variety interaction ( $P=0.0294)$.

\begin{tabular}{lrrrr} 
Effect & Num DF & \multicolumn{1}{c}{ Den DF } & \multicolumn{1}{l}{ F Value } & Pr $>$ F \\
\hline SiteType & 1 & 20 & 0.42 & 0.525 \\
BC & 1 & 20 & 1.27 & 0.2738 \\
SiteType*BC & 1 & 20 & 0.78 & 0.3886 \\
Var & 5 & 47 & 1.19 & 0.3273 \\
SiteType*Var & 5 & 47 & 0.86 & 0.5146 \\
BC*Var & 5 & 37 & 0.69 & 0.6313 \\
SiteType*BC*Var & 5 & 37 & 2.82 & 0.0294
\end{tabular}

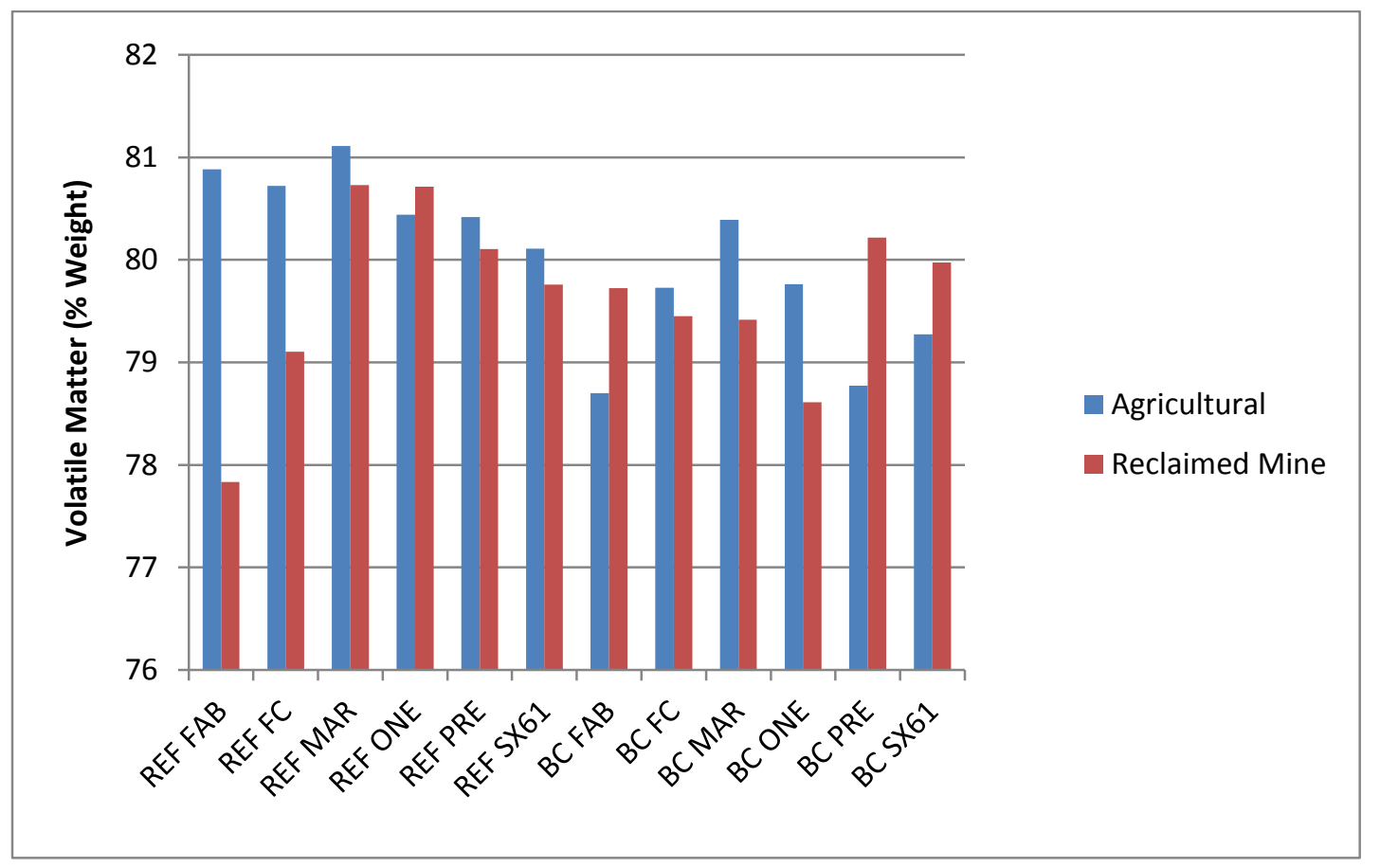

Figure 10. Volatile matter (\% weight) of Salix spp. samples by biochar, variety, and field trial site in West Virginia. A significant difference was observed for site type by biochar by variety interactions $(P<0.0294)$. The significant interaction between these variables is due to variety 'Oneida' having a lower volatile matter content in agricultural site types in the biochar amended plots and a higher volatile matter content in agricultural site types for reference plots. Volatile matter is displayed in percent weight.

\section{Moisture Content}

Moisture content in this study was $6.2 \%$ by weight. This is slightly higher than the $5 \%$ general guideline for coal. Since moisture content is related to heating value, heating value is expected to be lower than that of coal. Percent moisture is influenced by age, genetic controls, and environmental factors. Moisture content did not vary significantly between site, variety, 
treatment or any interactions among the variables, similar to the New York study by Tharakan et al., 2003.

Table 15. ANOVA table for moisture content of all Salix spp. biomass samples from West Virginia field trials. No significant effects were observed.

\begin{tabular}{lrrrr} 
Effect & $\begin{array}{r}\text { Num } \\
\text { DF }\end{array}$ & $\begin{array}{r}\text { Den } \\
\text { DF }\end{array}$ & $\begin{array}{r}\text { F } \\
\text { Value }\end{array}$ & Pr > F \\
\hline SiteType & 1 & 20.03 & 2.17 & 0.1567 \\
BC & 1 & 20.03 & 0.4 & 0.5332 \\
Type*BC & 1 & 20.03 & 0.02 & 0.8825 \\
Var & 5 & 84.38 & 0.82 & 0.5365 \\
SiteType*Var & 5 & 84.38 & 0.39 & 0.8519 \\
BC*Var & 5 & 84.38 & 0.72 & 0.6072 \\
SiteType*BC*Var & 5 & 84.38 & 0.96 & 0.4499
\end{tabular}

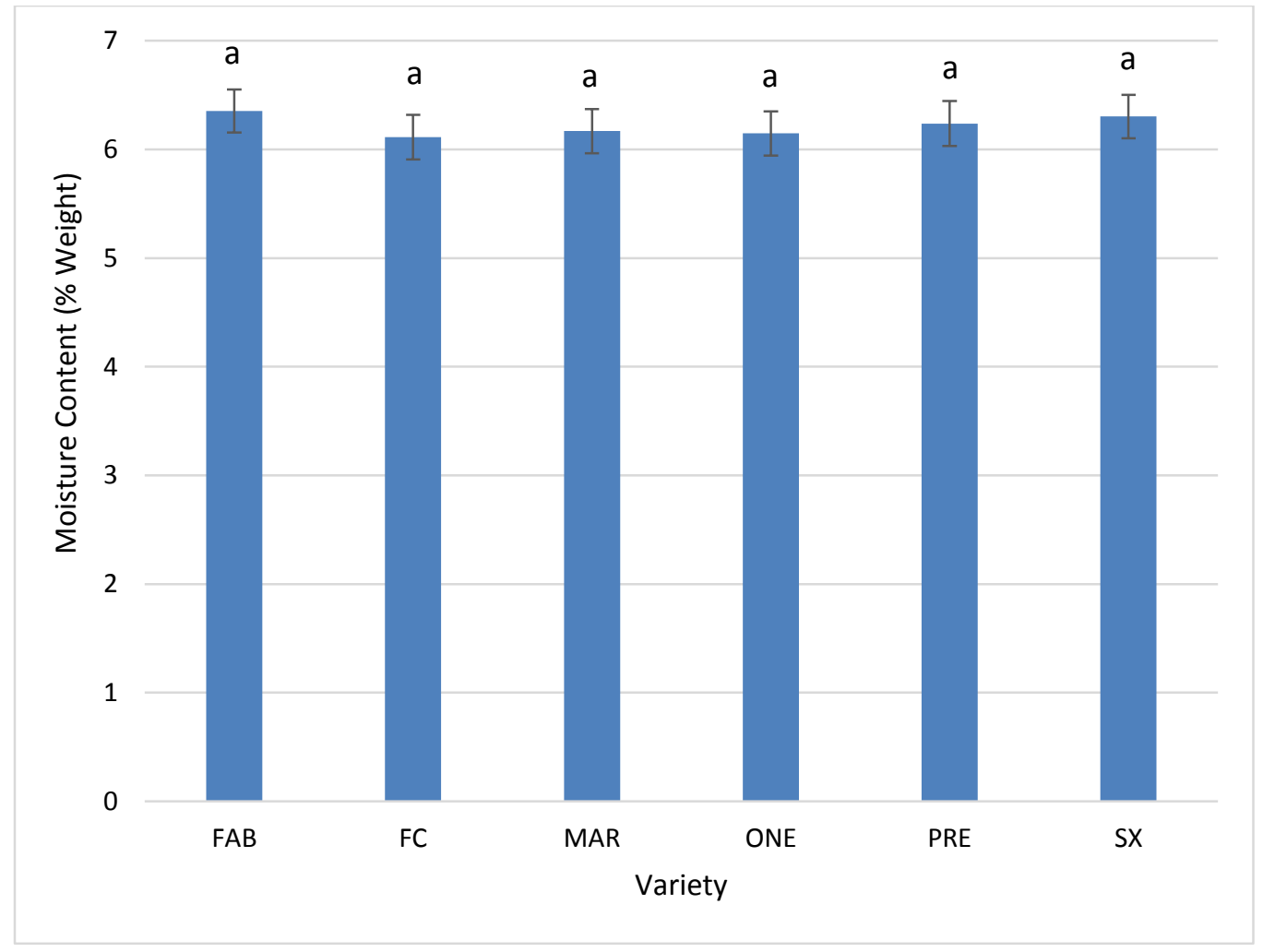

Figure 11. Moisture content (\% weight) of Salix spp. samples by variety from West Virginia field trials. No significant effects were observed. 


\section{Elemental Analysis of Biomass Composition}

No significant differences were observed in the elemental analysis of carbon, hydrogen, sulfur, or oxygen by percent weight. Average carbon content of all samples was $47.3 \%$ by weight. Average hydrogen content was $6.0 \%$ by weight. Average sulfur content was $0.33 \%$ by weight and average oxygen content was $45.4 \%$. Carbon, hydrogen, and sulfur contents were within the general guidelines provided by Demirbas (2004), and oxygen content was just slightly outside the guidelines of $35-45 \%$ by weight.

Average nitrogen concentration for samples in this study was $0.98 \%$ by weight. This is quite a bit higher than $0.34 \%$ and $0.36 \%$ observed in similar studies however lower than the typical $1.2 \%$ nitrogen found in coal. Differences were observed in nitrogen due to biochar $(P=0.0056)$, variety $(P=0.0385)$, and site type by biochar $(P=0.0259)$ (Table 15). Nitrogen concentrations for wood samples from biochar amended plots were significantly higher than in reference plots $(P=0.0056) ; 1.0544$ ( \pm 0.03687$)$ nitrogen by percent weight compared to 0.9080 $( \pm 0.03640)$ percent nitrogen by weight, respectively. This is likely due to biochar's capacity to increase nutrient availability in soils. Nitrogen content also differed significantly in the site by biochar interaction (Figure 11). Biochar amended plots were more effective at increasing nitrogen availability at agricultural sites than at reclaimed mine sites. The nitrogen content at both reclaimed mine sites was higher than for the agricultural sites. The biochar treatment may have been more effective at increasing nitrogen availability at agricultural sites due to its initially low availability. 
Table 16. ANOVA table for nitrogen content of Salix spp. samples in West Virginia field trials. Significant effects were observed for variables biochar $(P=0.0056)$ and variety $(P=0.0385)$, and the interaction site type by biochar $(\mathrm{P}=0.0259)$.

\begin{tabular}{lrrrr} 
Effect & Num DF & Den DF & F Value & Pr $>$ F \\
\hline SiteType & 1 & 108 & 3.65 & 0.0588 \\
BC & 1 & 108 & 7.98 & 0.0056 \\
SiteType*BC & 1 & 108 & 5.1 & 0.0259 \\
Var & 5 & 108 & 2.45 & 0.0385 \\
SiteType*Var & 5 & 108 & 0.56 & 0.7296 \\
BC*Var & 5 & 108 & 0.98 & 0.4363 \\
SiteType*BC*Var & 5 & 108 & 1.14 & 0.3446
\end{tabular}

Nitrogen also varied due to variety which seemed to be driven by the variety SX61,

which had low P-values when compared to the other varieties also producing the only significant difference in pairwise comparisons: varieties 'SX61' (1.14\% nitrogen by weight) and 'Fabius' (0.87\% nitrogen by weight) with a P-value of 0.0385. (Figure 12).

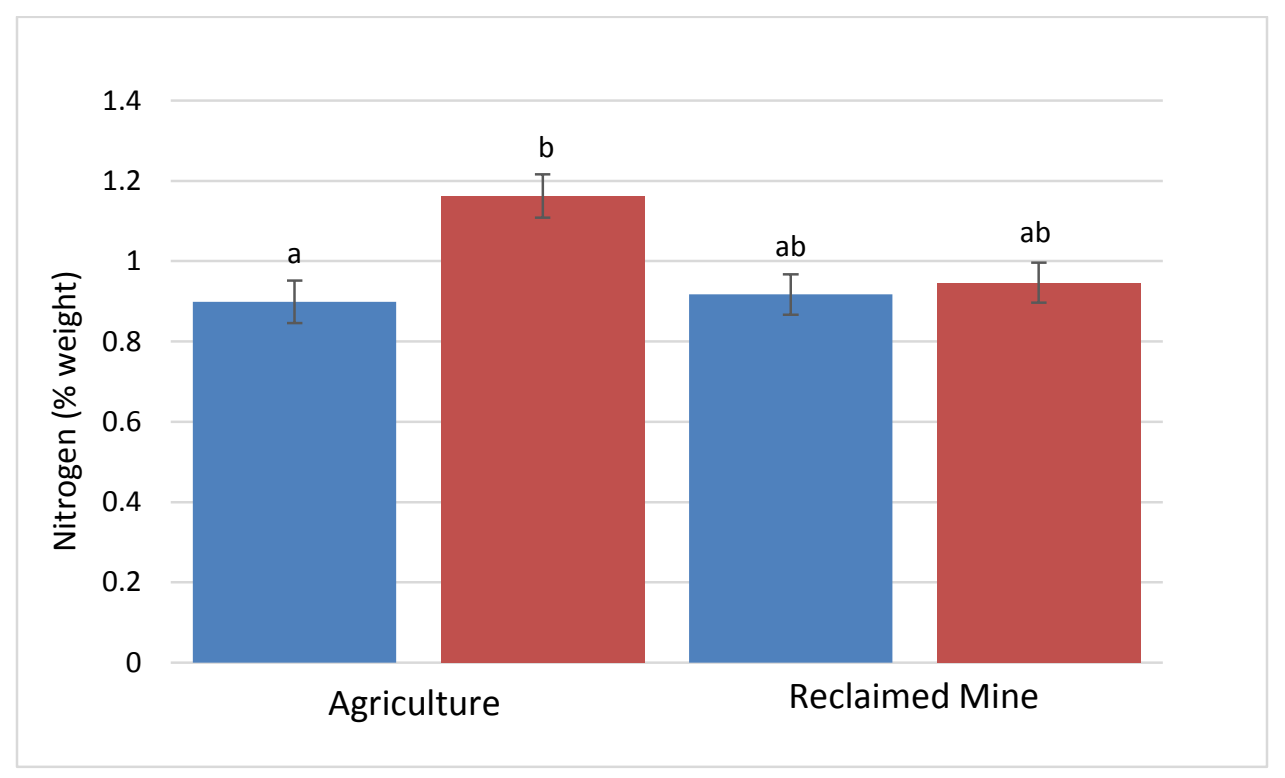

Figure 12. Nitrogen (\% weight) of Salix spp. samples by site type and treatment in West Virginia field trials. A significant biochar by site type interaction was observed $(P=0.0259)$. 


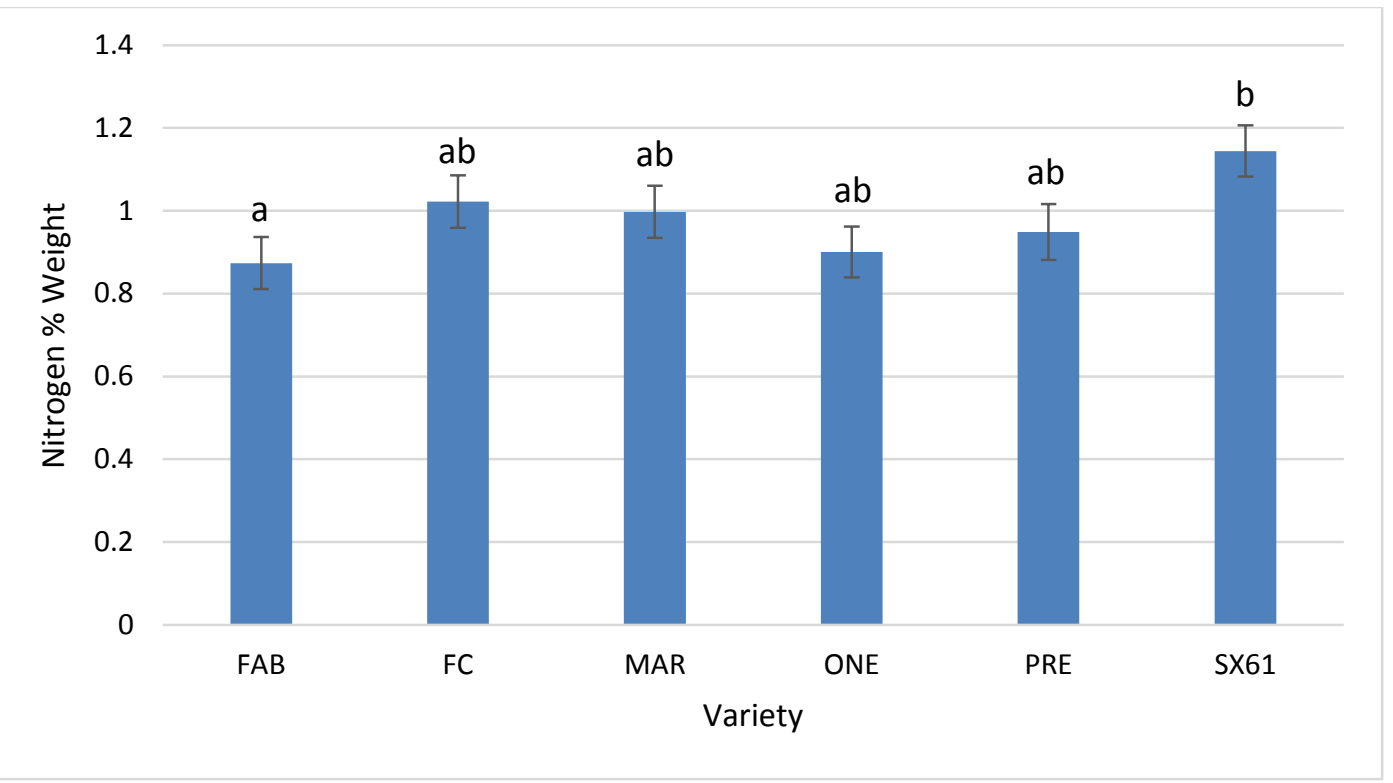

Figure 13. Nitrogen content (\% weight) of Salix spp. by variety for West Virginia field trials. A statistically significant difference was observed $(\mathrm{P}=0.0385)$.

\section{Heating Value}

Average BTU/lb for all samples is $7893.8(18.4 \mathrm{MJ} / \mathrm{kg})$. This falls within the estimates provided by the general guidelines for woody biomass. Those guidelines indicate $14-21 \mathrm{MJ} / \mathrm{kg}$ should be expected. Generally speaking, heating value is measured at the end of a rotation (after 3-4 years of growth). Bark is known to lower the average heating value of woody biomass and since these are samples from year one, bark makes up a higher proportion of the biomass so a lower heating value would be expected however this is not what is observed. BTU/lb did not show any correlations with factors that drive heating value such as ash or carbon.

BTU/lb values differed significantly by variety at $\alpha=0.05$ level ( $P=0.0045)$ (Table 16).

Differences were driven by variety 'Fish Creek' which had BTU/lb values significantly higher than varieties 'Fabius' ( $P=0.0348)$ and 'Marcy' $(P=0.0220)$ (Figure 13). Variations in heating value for varieties are likely due to the natural variation among cultivars that is expected due to the intentional maintenance of genetic diversity among cultivars. 
Table 17. ANOVA table for heating value of Salix spp. from West Virginia field trials. A significant variety effect was observed $(P=0.0045)$.

\begin{tabular}{lrrrr} 
Effect & Num DF & Den DF & F Value & Pr $>$ F \\
\hline SiteType & 1 & 18.46 & 0.86 & 0.3654 \\
BC & 1 & 18.46 & 0.14 & 0.7146 \\
SiteType*BC & 1 & 18.46 & 0.46 & 0.5056 \\
VAR & 5 & 88.34 & 3.68 & 0.0045 \\
SiteType*VAR & 5 & 88.34 & 0.86 & 0.5122 \\
BC*VAR & 5 & 88.34 & 1.84 & 0.113 \\
SiteType*BC*VAR & 5 & 88.34 & 1.17 & 0.3297
\end{tabular}

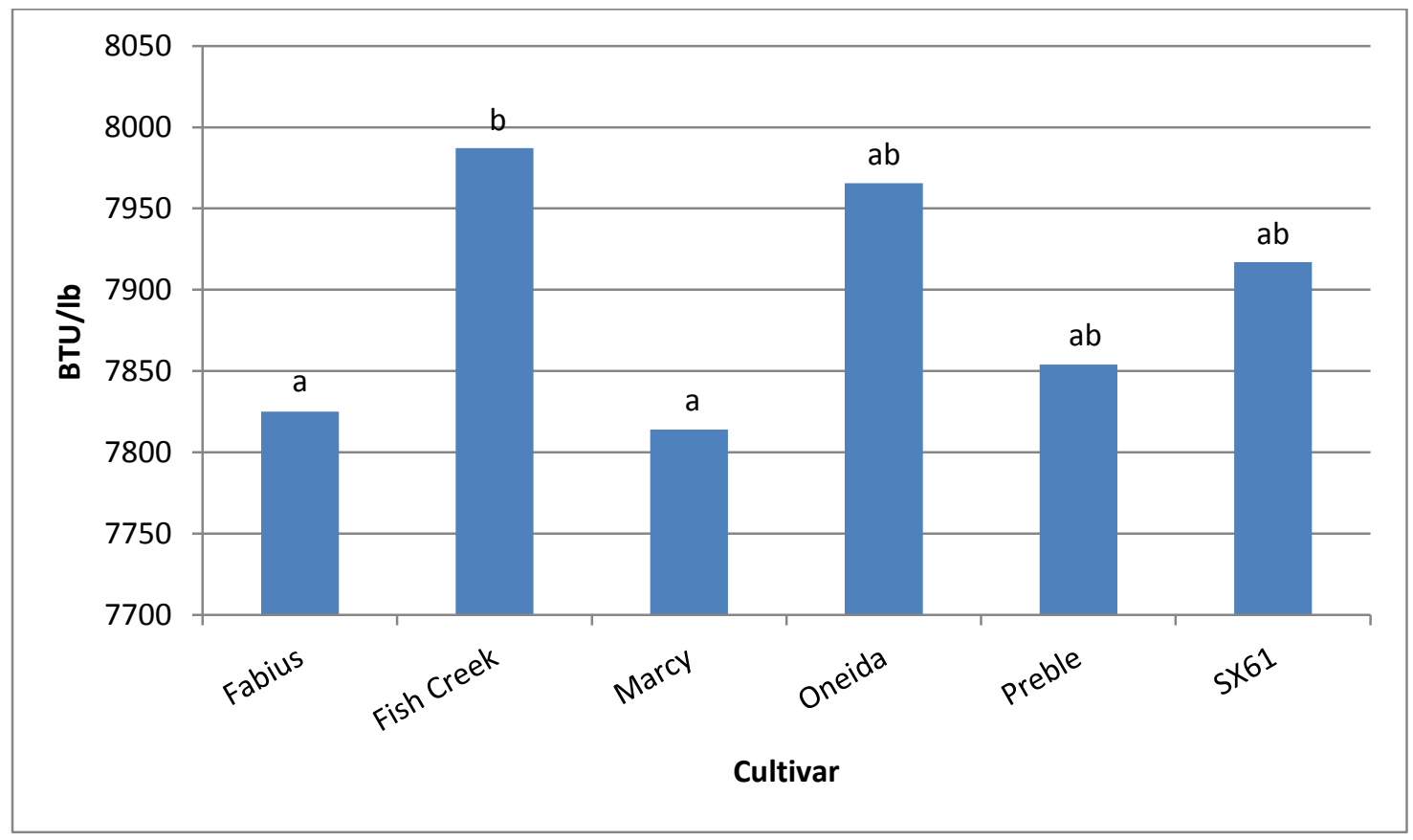

Figure 14. Estimated BTU/lb of Salix spp. by cultivar from West Virginia field trials. Significant differences are observed between 'Fish Creek' and varieties 'Fabius' and 'Marcy' ( $\mathrm{P}<0.0045)$. 


\section{Chapter 5}

\section{Conclusion}

\section{Summary of Findings}

This study achieved the objective of establishing growth and yield trials for shrub willow on marginal lands in West Virginia. This study is an analysis of year one data that will be part of a long term study on feasibility of growing Salix spp. as a bioenergy crop on reclaimed mine lands and marginal agricultural lands for incorporation into the energy market of West Virginia.

Although the results of this study assess only year one data, valuable insights into shrub willow cultivation using biochar on reclaimed mine sites and marginal agricultural sites have been gained.

Survivorship of all cultivars at all sites was lower than the anticipated $90 \%$ that has been demonstrated on prime agricultural land. Site 'Greenbrier' had the highest growth and yield, and the lowest mortality. This is likely due to the slightly higher mean annual rainfall and lower average temperatures. 'Greenbrier' also had more nitrogen available in the soils as well as more iron, manganese, and zinc than the three other sites.

Wood properties were generally within the general guidelines for woody biomass. Ash content was slightly higher ( $2.7 \%$ vs. $1 \%)$ as was nitrogen ( $0.98 \%$ vs. $0.35 \%)$. Ash content was likely higher than the general guidelines for woody biomass due to the age of the samples. Ash is typically measured at the end of a rotation (3-4 years) whereas in this study ash was measured at the end of the first growing season. The bark to wood ratio is higher at the end of the first growing season thereby raising the percentage of ash in the samples. Volatile matter 
was lower than general a guideline $(79.8 \%$ vs. $82 \%)$ which is beneficial for heating values and greenhouse gas emissions.

The insights into the use of biochar on marginal lands were arguably the most important implications of this study. The use of biochar proved to be fruitful in the improvement of soil structure and retention of essential nutrients for plant growth. This is demonstrated through higher growth, yield, and survivorship in biochar amended plots than reference plots at all sites. Additionally, biochar was more effective at reclaimed mine sites than agricultural sites. This may be due to reclaimed mine sites having a poorer soil structure and the biochar therefore having a greater positive effect on structure than at agricultural sites. The aggregate stability at both of the reclaimed mine sites was lower than the agricultural sites (34.7\% vs. $50.5 \%$ ). Aggregate stability is influenced by organic matter content, biological activity, and nutrient cycling; biochar likely improved these properties and thus improved growth, yield, and survivorship over non amended plots. Improved growth and yield in biochar amended plots in the first year of growth give willow saplings a competitive advantage over weeds. Additionally, biochar has shown long-term positive impacts in field studies and improved growth and yield in year one may be an indicator of higher yields in the long-term.

\section{Study Limitations}

As with all research, this study was subject to several limitations which are disclosed in this section. Primarily, the cuttings were shipped to Morgantown in late April of 2013. The field trials were not established until late May of 2013 and such the cuttings were stored in a cooler on the West Virginia University campus for approximately one month. Anecdotally, many of the cuttings had begun to send out shoots prior to planting. The month long storage time may have 
led to a higher than expected mortality rate.

Willow samples from different sites were stored for different lengths of time upon harvest prior to oven-drying. Samples were dried to constant weight, however the storage period prior to drying may have led to differences in moisture content.

Finally, lab analyses for heating value, thermogravimetric measurements, and elemental measurements were performed a single time due to the large number of samples and time intensiveness of the tests. More accurate data on these variables would have been achieved through multiple samples for each analysis.

\section{Ideas for Future Work}

There is much room for expansion of this project. First and foremost includes long-term monitoring of established field trials. Field trials were established in 2013 and 2014. Both sites will require analysis for the first rotation in 2016 and 2017 respectively. Furthermore, establishment and analysis of additional field trials may provide additional information on year one growth patterns, response to climatic events such as drought or extreme cold, and response to biochar in year one and beyond.

Expanding this research to include greenhouse experiments would also be prudent. Greenhouse experiments may provide insights into discrepancies in performance between cultivars in the field and in a controlled environment. Greenhouse experiments may also eliminate variables such as differences in soil properties across a site, planting depth, precipitation, climate, etc.

In both field and greenhouse experiments, the use of a portable photosynthesis system such as the LI-6400XT (LI-COR, Lincoln, NE) as a proxy for photosynthesis would provide 
information on the productivity of various cultivars as well as the effectiveness of biochar as a soil amendment.

\section{Literature Cited}

Abrahamson, L.P., D.J. Robison, T.A. Volk, E.H. White, E.F. Neuhauser, W.H. Benjamin, and J.M. Peterson. 1998. Sustainability and environmental issues associated with willow bioenergy development in New York (U.S.A.). Biomass and Bioenergy 15: 17-22. Abrahamson, L.P., T.A. Volk, L.B. Smart, and K.D. Cameron. 2010. Shrub Willow Biomass Producers Handbook. State University of New York, College of Environmental Science and Forestry. 
Arvizu, D., T. Bruckner, H. Chum, O. Edenhofer, S. Estefen, A. Faaij, M. Fischedick, G. Hansen, G. Hiriart, O. Hohmeyer, K. G. T. Hollands, J. Huckerby, S. Kadner, Å. Killingtveit, A. Kumar, A. Lewis, O. Lucon, P. Matschoss, L. Maurice, M. Mirza, C. Mitchell, W. Moomaw, J. Moreira, L. J. Nilsson, J. Nyboer, R. Pichs-Madruga, J. Sathaye, J. Sawin, R. Schaeffer, T. Schei, S. Schlömer, K. Seyboth, R. Sims, G. Sinden, Y. Sokona, C. von Stechow, J. Steckel, A. Verbruggen, R. Wiser, F. Yamba, T. Zwickel, 2011: Technical Summary. In IPCC Special Report on Renewable Energy Sources and Climate Change Mitigation [O. Edenhofer, R. Pichs-Madruga, Y. Sokona, K. Seyboth, P. Matschoss, S. Kadner, T. Zwickel, P. Eickemeier, G. Hansen, S. Schlömer, C. von Stechow (eds)], Cambridge University Press, Cambridge, United Kingdom and New York, NY, USA.

Baxter, L. and J. Koppenjan. 2004. Co-combustion of biomass and coal. Euroheat and Power (English Ed.) 1: 34-39.

Borzecka-Walker, M., A. Faber, and R. Borek. 2008. Evaluation of carbon sequestration in energetic crops (Miscanthus and coppice willow). International Agrophysics 22: 185-190.

Cameron, K., L. Smart, T. Volk, and L. Abrahamson. 2007. Salix purpurea 'Fish Creek.' The Research Foundation of State University of New York.

Campbell, J.E., D.B. Lobell, R.C. Genova, and C.B. Field. 2008. The global potential of bioenergy on abandoned agriculture lands. Enviornmental Science Technology

Chum, H., A. Faaij, J. Moreira, G. Berndes, P. Dhamija, H. Dong, B. Gabrielle, A. Goss Eng, W. Lucht, M. Mapako, O. Masera Cerutti, T. McIntyre, T. Minowa, K. Pingoud, 2011: Bioenergy. In IPCC Special Report on Renewable Energy Sources and Climate Change Mitigation [O. Edenhofer, R. Pichs-Madruga, Y. Sokona, K. Seyboth, P. Matschoss, S. 
Kadner, T. Zwickel, P. Eickemeier, G. Hansen, S. Schlömer, C. von Stechow (eds)],

Cambridge University Press, Cambridge, United Kingdom and New York, NY, USA.

Ciolkosz, D. 2010. Renewable and alternative energy fact sheet: characteristics of biomass as a heating fuel. The Pennsylvania State University, Ag Communications and Marketing.

Cook, J., J. Beyea. 2000. Bioenergy in the United States: progress and possibilities. Biomass and Bioenergy 18: 441-455.

Debolt, S. J.E. Campbell, R.Smith, Jr., M. Montross. And J. Stork. 2009. Life cycle assessment of native plants and marginal lands for bioenergy agriculture in Kentucky as a model for south-eastern USA. GCB Bioenergy: 1-9.

Demirbas, A. 2004. Combustion characteristics of different biomass fuels. Progress in Energy and Combustion Science 30: 219-230.

Dimitriou, I. and P. Aronsson. Willow for energy and phytoremediation in Sweden. FAO. Accessed 6/5/2013.

Draper. K. and T. Tomlinson. 2012. Poultry litter biochar: a US perspective. International Biochar Initiative

Fellet, G., L. Marchio, G. Delle Vedove, and A. Peressotti. 2011. Application of biochar on minetailings: effects and perspectives for land reclamation. Chemosphere.

Grushecky, S., Skousen, J., McGill, D., DiFazio, S. 2013. NEWBio Seed Grant.

Heller, M.C., G.A. Keoleian, M.K. Mann, and T.A.Volk. 2004. Life cycle energy and enviornemtnal benefits of generating electricity from willow biomass. Renewable Energy 29: 10231042. 
International Biochar Initiative. http://www.biochar-international.org/.

Jeffery, S., F.G.A. Verheijen, M. van der Velde, and A.C. Bastos. 2011. A quantitative review of the effects of biochar application to soils on crop productivity using meta-analysis. Agriculture, Ecosystems and Environment 144: 175-187.

Jones, D.I., J. Rousk, G. Edwards-Jones, T.H. DeLuca, D.V. Murphy. 2012. Biochar-mediated changes in soil quality and plant growth in a three year field trial. Soil Biology and Biochemistry 45: 113-124.

Kahru, K., T. Mattila, I. Bergstrom, and K. Regina. 2011. Biochar addition to agricultural soil increased $\mathrm{CH}_{4}$ uptake and water holding capacity - results from a short-term pilot field study. Agriculture, Ecosystems and Environment 140: 309-313.

Kwapinski, W. C.M.P. Byrne, E. Kryachoko, P. Wolfram, C. Adley, J.J. Leahy, E.H. Novotny, and M.H.B. Hayes. 2010. Biochar from biomass and waste. Waste Biomass Valor 1: 177-189. Labrecque, M., T.I. Teodorescu, and S. Daigle. 1997. Biomass productivity and wood energy of Salix species after 2 years growth in SRIC fertilized with wastewater sludge. Biomass and Bioenergy 12: 409-417.

Labrecque, M. and T.I. Teodorescu. 2003. High biomass yield achieved by Salix clones in SRIC following two 3-year rotations on abandoned farmland in southern Quebec, Canada. Biomass and Bioenergy 25: 135-146.

Lange, S., and L.A. Pellegrini. 2014. Study of the hydrogen potentiality from supercritical water gasification of different biomasses: thermodynamic analysis and comparison with experimental data. Chemical Engineering Transactions. 37: 175-180. 
Ledin, S. 1996. Willow wood properties, production, and economy. Biomass and Bioenergy 11: 75-83.

Lehmann, J., J. Gaunt, and M. Rondon. 2006. Biochar sequestration in terrestrial ecosystems - a review. Mitigation and Adaptation Strategies for Global Change 11: 403-427.

Lima, I.M., A.A. Boateng, and K.T. Klasson. 2009. Pyrolysis of broiler manure: char and product gas characterization. American Chemical Society 48: 1292-1297.

Major, J., M. Rondon, D. Molina, S.J. Riha, and J. Lehmann. 2010. Maize yield and nutrition during 4 years after biochar application to a Colombian savanna oxisol. Plant Soil 333: 117-128.

Mann, M.K. and P.L. Spath. 2001. A life cycle assessment of biomass cofiring in a coal fired power plant. Clean Prod Processes 3: 81-91.

Manomot Center for Conservation Sciences. 2010. Massachusetts Biomass Sustainability and Carbon Policy Study: Report to the Commonwealth of Massachusetts Department of Energy Resources. Walker, T. (Ed.). Contributors: Cardellichio, P., Colnes, A., Gunn, J., Kittler, B., Perschel, R., Recchia, C., Saah, D., and Walker, T. Natural Capital Initiative Report NCl-2010- 03. Brunswick, Maine.

McKendry, P. 2002. Energy production for biomass (part 1): overview of biomass. Bioresource Technology 83: 37-46.

Miller, R.O. and B.A. Bender. 2008. Growth and yield of poplar and willow hybrids in the central Upper Peninsula of Michigan. Michigan State University.

NEWBio. 2012. http://www.newbio.psu.edu/. The Pennsylvania State University. 
Novak, J.M, I. Lima, B. Xing, J.W. Gaskin, C. Steiner, K.C. Das, M. Ahminda, D. Rehrah, D.W. Watts, W.J. busscher, H. Schomberg. 2009. Characterization of designer biochar produced at different temperatures and their effects on loamy sand. Annals of Environmental Science 195-206.

Peterson, G.M. and J.K. Galbraith. 1932. The concept of marginal land. Journal of Farm Economics. 14:295-310.

Prins, M.J., K.J. Ptasinski, and F.J.J.G. Janssen. 2006. Torrefaction of wood: part 2. Analysis of products. Journal of Analytical and Applied Pyrolysis. 77: 35-40.

Rooney, D.C., K. Killham, G.D. Bending, E. Baggs, M. Weih, and A. Hodge. 2009. Mycorrhiza and biomass crops: opportunities for future sustainable development. University of Warwick. 1-31.

Ryu, C., Y.B. Yang, A. Khor, N.E. Yates, V.N. Sharifi, and J. Swithenbank. 2006. Effect of fuel properties on biomass combustion: Parti I. Experiments - fuel type, equivalence ratio and particle size. Fuel 85: 1039-1046.t

Serapiglia, M.J., K.D. Cameron, A.J. Stipanovic, L.P. Abrahamson, T.A. Volk, and L.B. Smart. 2013. Yield and woody biomass traits of novel shrub willow hybrids at two contrasting sites. Bioenergy Resources 6: 533-546. 4:1-8.

Serapiglia, M.J., M.C. Humiston, H. Xu, D.A. Hogsett, R.M. de Orduña, A.J. Stipanovic, and L.B. Smart. 2013. Enzymatic saccharification of shrub willow genotypes with differing biomass composition for biofuel production. Frontiers in Plant Science

Solaiman, Z.M., D.V. Murphy, and L.K. Abbott. 2012. Biochars influence seed germination and early growth of seedlings. Plant Soil 353: 273-287. 
Tharakan, P.J., T.A. Volk, L.P. Abrahamson, and E.H. White. 2003. Energy feedstock characteristics of willow and hybrid poplar clones at harvest age. Biomass and Bioenergy 25: $571-580$.

Tahvanainen, L., and V.M. Rytkonen. 1999. Biomass production of Salix viminalis in southern Finland and the effect of soil properties and climate conditions on its production and survival. Biomass and Bioenergy 16: 103-117.

Tang, Y., J.S. Xie, and S. Geng. 2010. Marginal land-based biomass energy production in China. Journal of Integrative Plant Biology 52: 112-121.

U.S. Department of Energy. Energy.gov. Accessed Sept. 6, 2013.

Vande Walle, I., N. Van Camp, L. Van de Casteele, K. Verheyen, and R. Lemeur. 2007. Shortrotation forestry of birch, maple, poplar and willow in Flanders (Belgium) I - biomass production after 4 years of tree growth. Biomass and Bioenergy 31: 267-275.

Volk, T.A., L.P. Abrahamson, C.A. Nowak, L.B. Smart, J.J. Tharakan, E.H. White. 2006. The development of short rotation willow in the northeastern United States for bioenergy and bioproducts, agroforestry and phytoremdiation. Biomass and Bioenergy 30: 715727.

Volk, T.A., T. Verwijst, P.J. Tharakan, L.P. Abrahamson, and E.H. White. 2004. Growing fuel: a sustainability assessment of willow biomass crops. Frontiers in Ecology and the Environment 2: 411-418.

Wicke, Birka. "Bioenergy production on degraded and marginal land: Assessing its potentials, economic performance, and environmental impacts for different settings and geographical scales." (2011). Chapter 1. 
